Published in final edited form as:

Crit Rev Food Sci Nutr. 2021 ; 61(2): 179-195. doi:10.1080/10408398.2020.1722941.

\title{
Science Dialogue Mapping of Knowledge and Knowledge Gaps Related to the Effects of Dairy Intake on Human Cardiovascular Health and Disease
}

\author{
Andrew W. Brown [Assistant Professor], \\ Department of Applied Health Science, Indiana University School of Public Health-Bloomington, \\ Bloomington, IN, USA, 47405. \\ Kathryn A. Kaiser [Assistant Professor], \\ Department of Health Behavior, School of Public Health, University of Alabama at Birmingham, \\ Birmingham, AL USA 35222
}

Andrew Keitt [Associate Professor],

Department of History, University of Alabama at Birmingham

\section{Kevin Fontaine [Professor],}

Department of Health Behavior, University of Alabama at Birmingham, Birmingham, AL, USA, 35294

\author{
Madeline Gibson [Program Director], \\ Dean's Office, School of Public Health, University of Alabama at Birmingham, Birmingham, AL, \\ USA, 35294

\section{Barbara Gower [Professor], \\ Department of Nutrition Sciences, University of Alabama at Birmingham}

\begin{abstract}
James M. Shikany [Professor of Medicine],
Division of Preventive Medicine, School of Medicine, University of Alabama at Birmingham, Birmingham, AL 35294 USA.
\end{abstract}

\section{Colby J. Vorland [Postdoctoral Fellow],} \\ Department of Applied Health Science, Indiana University School of Public Health-Bloomington, \\ IN, USA, 47405.
}

\section{Donald C. Beitz [Distinguished Professor],}

Departments of Animal Science and Biochemistry, Biophysics, and Molecular Biology, lowa State University, Ames, IA, USA 50011.

Dennis M. Bier,

\footnotetext{
Corresponding authors Andrew W Brown, PhD, SPH 116, 1025 E. Seventh Street, Bloomington, IN, 47405, awb1@iu.edu, David B Allison, PhD, SPH 111, 1025 E. Seventh Street, Bloomington, IN, 47405, allison@iu.edu.

Supplemental materials

1) Consolidated and anonymized interactive dialogue map: https://dx.doi.org/10.5967/2nxz-f171

2) Files to generate the dialogue map: https://dx.doi.org/10.5967/mj87-0647

3) Instructions and guidelines provided in advance of Phase 1.

4) Instructions and guidelines provided in advance of Phase 2.
} 
Baylor College of Medicine, Department of Pediatrics, Children's Nutrition Research Center, Houston, Texas 77030

\section{J. Thomas Brenna,}

J. Thomas Brenna, Dell Pediatric Research Institute, Depts of Pediatrics, of Chemistry, and of Nutrition, University of Texas at Austin, Texas 78723.

David R Jacobs Jr, Division of Epidemiology and Community Health, School of Public Health, University of Minnesota, Minneapolis, Minnesota, 55454.

\section{Penny Kris-Etherton [Distinguished Professor of Nutrition],}

Department of Nutritional Sciences, Pennsylvania State University, University Park, PA, 16802

\section{Kevin Maki [Chief Scientist],}

Midwest Biomedical Research/Center for Metabolic and Cardiovascular Health; 211 E. Lake Street, Suite 3, Addison, IL 60601.

\section{Michael Miller [Professor of Cardiovascular Medicine],}

Epidemiology \& Public Health, Dept of Medicine, University of Maryland School of Medicine, Baltimore, MD 21201

\section{Marie-Pierre St-Onge,}

Division of Endocrinology and Sleep center of excellence, Department of Medicine, Columbia University Irving Medical Center, New York, NY 10032

\section{Margarita Teran-Garcia [Research Assistant Professor],}

Extension Specialist Hispanic Health Programs, Department of Human Development and Family Studies, Cooperative Extension, Division of Nutritional Sciences, Carle Illinois College of Medicine, University of Illinois Urbana-Champaign. Urbana, Illinois, 61801

\section{David B. Allison [Dean, Distinguished Professor, and Provost Professor]}

School of Public Health, Indiana University, 1025 E. $7^{\text {th }}$ Street, Bloomington, IN 47405

\section{Abstract}

Dairy has been described as everything from a superfood to a poison; yet, arguments, assumptions, and data justifying these labels are not always clear. We used an issue-based information system, "dialogue mapping ${ }^{\mathrm{TM}}$," to summarize scientific points of a live panel discussion on the putative effects of dairy on cardiovascular diseases (CVD) from a day-long session among experts in nutrition and CVD. Dialogue mapping captures relations among ideas to explicitly, logically, and visually connect issues/questions, ideas, pro/con arguments, and agreements, even if discussed at different times. Experts discussed two propositions: for CVD risk, consumption of full-fat dairy products, 1) should be minimized, in part because of their saturated fat content, or 2) need not be minimized, despite their saturated fat content. The panel discussed the dairy-CVD relation through blood lipids, diabetes, obesity, energy balance, blood pressure, dairy bioactives, biobehavioral components, and other putative causal pathways. Associations and effects reported in the literature have varied by fat content of dairy elements considered, study design, intake methods, and biomarker versus disease outcomes. Two conceptual topics emerged from the discussion: 1) individual variability: whether recommendations should be targeted only to those at high CVD 
risk; 2) quality of evidence: whether data on dairy-CVD relations are strong enough for reliable conclusions - positive, negative, or null. Future procedural improvements for science dialog mapping include using singular rather than competing propositions for discussion.

\section{Keywords}

Dairy; dialogue mapping; cardiovascular disease

\section{Introduction}

Milk, cheese, yogurt, and other dairy foods have been, and are still to this day, described as 'superfoods,' the 'ultimate recovery' food, laden with artery-clogging saturated fat, loaded with sodium, promoters of satiety, outstanding sources of protein and calcium, liquid-sugar calories, the most wholesome of foods, and in other ways. Yet, if we move past the rhetoric and presuppositions, where does the evidence stand? This question is sometimes difficult to assess because the arguments, assumptions, and data underlying stated propositions are often not clearly articulated.

Dairy has been included in each iteration of the Dietary Guidelines for Americans, but recommendations have been inconsistent as to whether dairy consumed should be non-fat (partial FDA definition: "less than 0.5 gram (g) of fat per reference amount customarily consumed", from 21 CFR §101.62), low-fat (partial FDA definition: "reference amount customarily consumed greater than $30 \mathrm{~g}$ or greater than 2 tablespoons and contains $3 \mathrm{~g}$ or less of fat per reference amount customarily consumed"), reduced-fat (partial FDA definition: "contains at least 25 percent less fat per reference amount customarily consumed"), or full-fat. For instance, the 1980 Dietary Guidelines suggested that "[i]f you prefer whole milk to skim milk, you can reduce your intake of fats from foods other than milk,"(U. S. Department of Health and Human Services and U. S. Department of Agriculture, 1980) while the 2005 Guidelines recommended " $[w]$ hen selecting and preparing ... milk or milk products, make choices that are lean, low-fat, or fat-free" (U. S. Department of Health and Human Services and U. S. Department of Agriculture, 2005). The Dietary Guidelines have followed the broader trends of recommending lower fat in the diet, and although more recent recommendations have started to ease cautions about dietary fat, in part because of the hypothesis that general low-fat recommendations resulted in deleterious health consequences for the population, the guidelines still suggest reduced or non-fat dairy (U. S. Department of Health and Human Services and U. S. Department of Agriculture, 2015). The justifications for these recommendations are not always discussed in precise terms. The range of considerations for dairy and health are many: bioactive compounds in dairy fat, bioactives in non-fat fractions, saturated fat content, metabolizable energy, ethics of animal agriculture and health of animals, potential effects on health of the environment, sugar content, hydration, protein content, calcium content, and other factors. Therefore, recommendations about whether or how much dairy should be consumed need to clearly specify the types of dairy products being considered for each specific outcome. We limit our discussion here to questions related to direct consumption of dairy on health outcomes in the humans consuming the dairy, with a particular focus on cardiovascular 
diseases (CVD) broadly. Questions of ethics, environment, and other disease states, while important to consider, are beyond the scope of this project and discussants.

This project uses a method for exploring opinions amongst experts known as "issue mapping" or "dialogue mapping"(Conklin, 2005). Dialogue mapping emerged out of the work of Horst Rittel and Werner Kunz, scholars of design science and urban planning at the University of California, Berkeley and the University of Heidelberg. Rittel and Kunz were interested in ill-defined, socially complex problems-problems they characterized as "wicked"- and they went on to develop an "Issue-Based Information System" (IBIS), a simple yet powerful grammar for representing issues, ideas, and arguments for clarifying group deliberation and decision making. IBIS forms the basis of dialogue mapping, pioneered by a protégé of Rittel's, Jeff Conklin. Conklin trademarked the term "dialogue mapping" to distinguish it from other methods of facilitation. Dialogue mapping is a method by which trained facilitators can document and summarize a meeting in real time to capture the relations between the statements and questions made by the meeting participants. Whereas the frequently used method of taking minutes of a meeting follows a discussion in chronological order, dialogue mapping explicitly, logically, and visually connects thoughts, propositions, points, and counterpoints, even if they are discussed at different times.

We used dialogue mapping to extract from a group of highly knowledgeable experts the points on which they agree and disagree. These experts have opined about and conducted research on the effects of dairy on health, with varied methods, viewpoints, and research outcomes. The map is facilitated by allowing all participants to see and respond to the map as it develops. This project therefore digs deeper than determining whether experts agree or disagree, to instead investigating the issues on which they agree or disagree and why they may disagree. Furthermore, the approach can be used to determine whether those disagreements were based on expert opinion or evidence. Thus, the results discussed herein highlight points of disagreement that can ostensibly be clarified by more research.

\section{Methods}

\section{Overall structure of project}

This project was conducted in three phases. The first phase consisted of a pilot session, in which the methods were tested and refined, held in March 2017. The dialogue map of this first session was not used for content analysis because the purpose was to assess feasibility of the process for the topic and scope. The second phase, held in November 2017, also consisted of a single session that built on the lessons learned from the first phase (described below). The results presented herein are derived from the second session. The third phase involved distillation of the dialogue map by the investigators, confirmation of information captured from the panel participants, and construction of the present article.

\section{Definition of dairy}

The charge of the panel began by operationally defining dairy for the sake of the activity. We used the USDA My Plate definition(U. S. Department of Agriculture, 2018): “All fluid milk products and many foods made from milk are considered part of [the dairy] food group. 
Foods made from milk that retain their calcium content are part of the group. Foods made from milk that have little to no calcium, such as cream cheese, cream, and butter, are not." In addition, the panel was advised that, although evidence from studies on sheep and goat's milk, animal models, or other sources may inform perspectives, conclusions were to be made about the causal effects of bovine dairy consumption on human health. Thus, intermediate endpoints, individual dairy constituents, and non-human studies could be considered but only in the context of how such evidence related to or was judged to be informative about dairy and human health.

\section{Phase 1: Pilot session}

Focus and purpose-The purpose of the Phase 1 'dress rehearsal' was to pilot test and refine the procedures to be used in the final expert panel session (Phase 2). In Phase 1, several aspects of the activity were tested, including the adequacy of people in various roles to facilitate the process, the appropriate amount of time needed to generate a useful Science Dialogue Map, and to evaluate whether the Science Dialogue Map can easily be translated to a subsequent evidence-mapping process.

The first dialogue mapping was centered on two different propositions:

1A. What recommendation does the current science support pertaining to the effects of regular consumption of dairy foods (non-fat, reduced-fat, or full-fat) on health with respect to increased risk or severity of CVD?

1B. What recommendation does the current science support pertaining to the effects of regular consumption of dairy foods (non-fat, reduced-fat, or full-fat) on health with respect to increased risk or severity of type 2 diabetes mellitus (T2DM)?

Selection and invitation of participants-Persons involved in Phase 1 served in five different roles.

1. Expert Panelist: We convened a body of seven experts from the U.S. and Canada (TK, $\mathrm{PJ}$, MPSO, VF, KM, DJ, and BG) with the goal of achieving complementary expertise in nutrition, obesity, CVD, and T2DM among academicians who have expressed divergent perspectives on these topics. Panelists were identified based on literature searches, expert networks, and snowball recruitment (i.e., those who declined often recommended someone else). The investigative team also solicited recommendations from the sponsor on panelists but retained final authority to invite and select the panelists.

2. Map Facilitator: The function of the Map Facilitator (AK) was to actively map the issues discussed in the sessions, from questions about the functional definition of dairy, to subsequent questions to refine the points in support of or refuting various ideas proposed. The Map Facilitator connected the ideas in real-time using the Compendium software (version 1.7.1, Milton Keynes, United Kingdom) projected on a large display for the whole panel to see throughout the sessions. The Map Facilitator asked for clarification, reiterated the statements made, and confirmed the appropriate relation among the nodes.

Crit Rev Food Sci Nutr. Author manuscript; available in PMC 2022 January 01. 
3. Scientific Facilitator: Along with the Map Facilitator, the Scientific Facilitator (DBA) worked to clarify the conversation in terms of the relation of comments to existing nodes on the map. The Scientific Facilitator also assisted in clarifying terminology used in the Science Dialogue Maps and asked questions, but remained neutral to the panelists' points of agreement and disagreement.

4. Guide and Worker: This role was composed of the investigative team (KAK, AWB, JS, KF, MG) who arranged the sessions, provided literature searches to supplement discussions, provided real time literature references or other information to clarify points of confusion or contention that could be resolved by extant literature, and drafted summaries. They also worked with the Map Facilitator and Scientific Facilitator to clarify terms and abbreviations in preparation for the meeting.

5. Observer: Three attendees selected by the funding agency were invited to observe the dialogue mapping meetings, but were not allowed to participate in the formal dialogue. Furthermore, they were not allowed to serve as co-authors of this publication, and had no editorial authority over any resulting presentations or publications.

Setting and meeting structure-Prior to arriving, participants were provided with instructions and guidelines (see supplemental materials), as well as some reviews to stimulate discussion (Aune, Norat, Romundstad, \& Vatten, 2013; Babio et al., 2015; Chen, Pan, Malik, \& Hu, 2012; Guasch-Ferre et al., 2017; Ivey et al., 2011; Kushi, Lenart, \& Willett, 1995; Ludwig and Willett, 2013; Machin, Park, Alkatan, Mouton, \& Tanaka, 2014, 2015; Menotti et al., 1999; Mikkila et al., 2009; Nicklas, O’Neil, \& Fulgoni, 2015; Petersen, Clifton, Blanch, \& Keogh, 2015; Prevention;, 2012; Tian et al., 2015). Participants were required to arrive the night before the meeting to attend a social dinner and to ensure attendance at the start of the meeting the next morning. Participants were required to attend the entirety of the mapping session. The session setting was a small classroom with a projector and screen, a computer, and a semi-circle of tables oriented toward the screen. Guides and Workers and Observers sat in the back of the room, while the Map Facilitator, Scientific Facilitator, and the Expert Panelists populated the semi-circle tables. The session began with a general orientation, including a review of the dialogue mapping process, the charge of the panel, and a reminder to remain focused on the session (e.g., electronic devices were to be used only to support the dialogue). Proposition 1A (CVD) was considered first; a small break was taken near lunch, followed by a working lunch. After lunch, Proposition 1B (T2DM) was considered.

Lessons learned-Several procedural issues were identified for refinement for Phase 2, including how the Map and Scientific Facilitators worked together to both advance and document the dialogue. Guides and Workers became more familiar with the types of data and questions that Expert Panelists may require additional information about, and thus Phase 2 included a collection of systematic reviews sent prior to the session for the Expert

Panelists' review (see Phase 2). Additionally, we determined that attempting to address two propositions as complex as dairy on two aspects of health was too much to accomplish in a single-day dialogue mapping session. Because the discussion about Proposition 1B was less 
robust and contained much less disagreement, Phase 2 was limited to a discussion of heart disease (related to Proposition 1A).

\section{Phase 2: Final dialogue mapping session}

Focus and purpose-As a result of the outcomes of the discussion in Phase 1, the dialogue map in Phase 2 was constructed by presenting the new panel of participants with two propositions:

2A. Consumption of full-fat dairy products, in part because of their saturated fat levels, should be kept to a minimum for the purposes of reducing the risks of heart disease.

2B. Consumption of full-fat dairy products, despite their saturated fat levels, need not be kept to a minimum for the purposes of reducing the risks of heart disease.

The structure was also different from Phase 1: two conflicting propositions were presented, rather than two open-ended propositions.

Selection and invitation of participants-As in Phase 1, participants filled the same five roles for Phase 2. Expert Panelists (PK, DCB, MM, VF, BL, MT, TB, DB) were recruited for their collective focus and expertise on dairy and CVD. We were particularly interested in identifying a balance of individuals who, on the basis of their expertise and understanding of the literature, would be predisposed to arguing in favor of Proposition 2A or 2B. We sought individuals who were comfortable arguing their viewpoint against others and were likely to do so collegially (engaging debaters, not polemicists), while also representing a variety of relevant expertise (e.g., clinical outcomes, nutrition science, dairy science, epidemiology, biochemistry). The investigative team also solicited recommendations from the sponsor on panelists but retained final authority to invite and select the panelists. AK again served as Map Facilitator, DBA again served as Scientific Facilitator, and the investigative team again served as Guides and Workers. Five Observers were scheduled to attend and were subject to the same constraints with respect to their participation as in Phase 1.

Setting and meeting structure-Pre-meeting materials were updated between Phases 1 and 2. Prior to arriving, participants were provided with instructions and guidelines (see supplemental materials), as well as a collection of systematic reviews and meta-analyses (Alexander et al., 2016; Bordoni et al., 2017; Crichton, Bryan, Buckley, \& Murphy, 2011; de Goede, Geleijnse, Ding, \& Soedamah-Muthu, 2015; de Goede, Soedamah-Muthu, Pan, Gijsbers, \& Geleijnse, 2016; Ding et al., 2017; Drouin-Chartier, Brassard, et al., 2016; Dumas et al., 2017; Geng, Qi, \& Huang, 2017; Gibson, Makrides, Smithers, Voevodin, \& Sinclair, 2009; Labonte, Couture, Richard, Desroches, \& Lamarche, 2013; Larsson, Crippa, Orsini, Wolk, \& Michaelsson, 2015; Liang, Zhou, Kwame Amakye, Su, \& Zhang, 2016; Magarey, Baulderstone, Yaxley, Markow, \& Miller, 2015; McGrane et al., 2011; Mente, de Koning, Shannon, \& Anand, 2009; Mullie, Pizot, \& Autier, 2016; Ndanuko, Tapsell, Charlton, Neale, \& Batterham, 2016; Pasin and Comerford, 2015; Pimpin, Wu, Haskelberg, Del Gobbo, \& Mozaffarian, 2016; Ralston, Lee, Truby, Palermo, \& Walker, 2012; Schwab et al., 2014; Soedamah-Muthu, Verberne, Ding, Engberink, \& Geleijnse, 2012; Sun and Buys, 
2015; Thorning et al., 2017; Wu and Sun, 2017). These reviews included RCTs, but were not necessarily exclusively RCTs, and may have only reviewed (not meta-analyzed) the studies. Together, these references were expected to include most RCTs to inform them questions at hand.

The Phase 2 dialogue mapping session was held in a hotel conference room in a hub airport city (Chicago, IL, USA) to simplify travel arrangements and to ensure all participants arrived on time and remained focused throughout the event. As in Phase 1, a social dinner was held the night before and most participants attended. The mapping session began with an early breakfast, followed by four hours of mapping discussion and a break for lunch. After lunch, participants engaged in four more hours of mapping discussion that included an afternoon break. Other details were similar: the Expert Panelists, Map Facilitator, and Scientific Facilitator were arranged around the screen, with Guides and Workers in the periphery for additional documentation and session support. Observers were located in the back of the room and did not participate or contribute.

\section{Phase 3: Map refinement, distillation, and publication}

Anonymizing, consolidating, and distilling the nodes-The purpose of this project was not to determine who agrees or disagrees with certain lines of evidence, but rather on what scientific grounds an expert may agree or disagree with a proposition; therefore anonymizing the statements or contributions to nodes is essential. In addition, throughout the course of discussion, similar ideas arose multiple times but in different contexts; so, similar or related statements in different branches of the map were consolidated. Finally, the points of conversation were distilled by AWB, AK, and KAK to organize and summarize without loss of content into propositions that have either already been or ostensibly could be answered by further research.

Scope and interpretation of this article-This article summarizes expert discussions about dairy and CVD as of the November 2017 meeting, and therefore considered literature that was available prior to the meeting. We recognize additional work has been completed since the meeting, such as an entire special issue dedicated to systematic reviews of dairy and health (Gil and Ortega, 2019). This document should therefore be interpreted in light of 1) the methodological approach of using dialogue mapping to probe a nutrition-chronic disease relation; 2) the dates of data available to be considered for discussion; 3) the scope being a summary of an expert discussion rather than a consensus document, such as that by Thorning et al. (Thorning, et al., 2017); and 4) the value of expert evaluation in determining present strengths and weaknesses of evidence while also identifying research priorities for future investigations.

\section{Results and Discussion}

Dialogue map

Figure 1 shows a static image of the consolidated and anonymized map. Within the map, several groupings of nodes are labeled as "node groups" that are summarized in the next section. The interactive version of the map can be viewed at https://dx.doi.org/10.5967/2nxz- 
f171. Note that nodes marked with $*$ or $^{\mathrm{T}}$ indicate that the node has additional details or a publication tagged in it, respectively, when the node is clicked on in the interactive version. Expanded portions of the map are presented with each section below as separate figures.

\section{Key points}

Because Propositions 2A and 2B were essentially complements of each other, some similar points were brought up in the discussion of each. We summarize below some general themes as organized into 'Node Groups' (NG). These NGs are, in turn, summarized in a conceptual schematic shown in Figure 2, and tied to specific parts of the putative relation between dairy and CVD.

Low density lipoproteins and CVD-A substantial portion of the conversation revolved around the relation between dairy and LDL, particularly referring to LDL cholesterol (LDLC; NG1, NG2, and NG3, Figure 3). In fact, one of the Panelists questioned, "To what extent is this the central issue [being discussed]?" Frequently, discussions about the effects of dairy on CVD broadly take the form of "dairy contains saturated fatty acids; saturated fatty acids raise LDL-C; therefore, dairy will raise LDL-C." In turn, the reasoning is continued as "LDL-C is a risk factor for CVD, and thus full-fat dairy will increase CVD risk." Yet, the panel discussed a study in which there was no difference between full- or reduced-fat cheeses (Raziani et al., 2016), and a systematic review that concluded "there is no apparent risk of potential harmful effects of dairy consumption, irrespective of the content of dairy fat, on a large array of cardiometabolic variables, including lipid-related risk factors..." (Drouin-Chartier, Cote, et al., 2016). However, the panel also discussed another metaanalysis that concluded butter increased LDL-C compared to cheese, yet cheese increased LDL-C compared to foods with a higher ratio of polyunsaturated to saturated fatty acids (de Goede, et al., 2015). If, as one panelist questioned, the dairy-LDL-C link is the central issue, there is disagreement about the influence of full-fat dairy's effects on LDL-C that may depend on what it is compared against, among other factors.

Dairy trans-fats were discussed in the relation between dairy and LDL-C (NG2). The sentiment was generally that the amounts of trans-fats in dairy were small and unlikely to have large effects (e.g., (A. W. Brown, Trenkle, \& Beitz, 2011)). However, because little evidence exists on isolated dairy trans-fats, and most trans-fat evidence is about industrial produced trans-fats, there was an overall agreement that the evidence was insufficient to make strong conclusions about the isolated effects of dairy trans-fats and LDL-C.

Finally, the relation between LDL-C and CVD more generally was also discussed (NG3), not necessarily with a focus on dairy, per se. Specifically, comments were raised about whether total LDL-C was the appropriate lipoprotein biomarker to consider. Research has expanded in recent years to focus more on lipoprotein subclasses (e.g., small, dense LDL particles), specific apolipoproteins (e.g., apoB), or LDL particle numbers. The evidence of a causal effect of dairy on these subspecies of lipoproteins was not seen as being robust in the literature, with more work to be done. In addition, the panel noted the challenge of detecting effects of dairy on blood lipids in the age of statins and other pharmaceutical treatments. In years past, decreases in blood cholesterol from dietary and lifestyle therapies may have been 
in the $10-15 \%$ range, whereas with the background of statins and other therapies, such decreases may not be achievable.

Diabetes-Diabetes is a potential causal pathway between dairy intake and changes in CVD risk because the leading cause of death among people with T2DM is CVD (NG5, Figure 4). However, the causal role of dairy in improving T2DM and its risk factors was generally felt to be lacking sufficient evidence, with some protective associations shown in observational studies (Drouin-Chartier, Brassard, et al., 2016; Dumas, et al., 2017). Further uncertainty was mentioned with respect to causes of T2DM more generally, such as through energy balance and obesity (below).

Obesity and energy balance-The discussion of obesity and energy balance stemmed from the discussion of whether full-fat dairy was contributing to higher energy intake (NG6, Figure 4). Indeed, if dairy is contributing to lower obesity, it could partially explain the negative associations described above for T2DM (NG5). Conversely, if full-fat dairy contributes to weight gain or excess energy intake, it would be of concern given the current obesity pandemic. This part of the conversation was divided into three overarching topics. First, there was an overall conversation of which foods and how much energy people are or should be consuming in general. Here, we summarize only conversations about dairy itself; other nodes about Dietary Reference Intakes and energy requirements are on the map. Key to this conversation was whether introduction of dairy foods, notably full-fat dairy foods, were resulting in lower intake of other essential foods and nutrients in the overall diet, especially when maintaining energy balance. Multiple analyses (Mente, et al., 2009; Ndanuko, et al., 2016; Schwab, et al., 2014) have tried to tease out differences amongst types of dietary fat, dietary factors, or dietary patterns and CVD or CVD risk factors. The results are ambiguous, with different subgroups of foods and people behaving differently depending on differences in physiology and other factors. One key limitation is that analyses of differences in dietary fat from self-reported data do not distinguish which food exchanges (and, thus, the associated nutrients with the foods rather than just the fatty acid compositions) are occurring when dairy is being substituted or when dairy is being added to or removed from the diet.

The second discussion focused on the effects of full-fat dairy on body weight. The general consensus is the effects are likely minimal [see "Assorted Studies" node; e.g., (Mozaffarian, Hao, Rimm, Willett, \& Hu, 2011)]. An interesting path for future research is determining what effect full-fat dairy may have in populations of older adults, particularly those with frailty, where weight gain or maintenance, particularly lean mass, may be important. Furthermore, there was a particular focus on the background diet and energy balance, with some evidence suggesting that dairy may result in fat loss or maintenance of lean mass under energy-restricted conditions (Booth, Huggins, Wattanapenpaiboon, \& Nowson, 2015; Geng, et al., 2017; Stonehouse et al., 2016), although high dairy intake without energy restriction may increase body weight (Geng, et al., 2017). A more nuanced question posed was whether isocaloric substitutions would be expected to have a meaningful differential effect on body weight or fat, with a panelist noting that lean mass gain could be considered beneficial. A challenge to this line of evidence is the level of experimental control required, 
namely that a small difference in compliance with purportedly isocaloric conditions could have a relatively large effect. Evidence for total fat, dairy fat, dairy protein, and other dairy components (Phillips and Zemel, 2011) were discussed, with evidence indicating that both calcium-dependent and -independent (e.g., calcitriol, branched-chain amino acids) mechanisms may mediate the relation between dairy and body composition (Phillips and Zemel, 2011).

Finally, panelists discussed whether full-fat versus reduced- or non-fat mattered for energy balance in practice. Although there was some sentiment expressed supporting the view that all sources of metabolizable energy were equivalent with respect to energy balance, some evidence suggests that reduced- or non-fat dairy actually resulted in increased weight compared to full-fat dairy (Key, Cantarero, Cohen, Conn, \& Cerami, 2016). Together, the implication is that lower fat dairy may have resulted in over-consumption of energy, possibly through the higher sugar content of reduced-fat products (e.g., sweetened low-fat yogurt), though evidence of this mechanism was sparse or equivocal (see Proposition $2 \mathrm{C}$ below that arose during the Phase 2 discussion).

Blood Pressure-Another suggested pathway between dairy and CVD is through effects on blood pressure (NG7, Figure 5). Given the mineral content of some dairy products, namely potassium, calcium, and magnesium contents, some presume that dairy should result in lower blood pressure. Indeed, some studies have demonstrated that the addition of non-fat dairy to a diet results in lower blood pressure (Machin, et al., 2014, 2015). There was little discussion about sodium other than noting that the addition of low sodium cheese, reducedfat dairy, and non-fat dairy as part of a Dietary Approaches to Stop Hypertension (DASH) diet lowers blood pressure (Derkach, Sampson, Joseph, Playdon, \& Stolzenberg-Solomon, 2017; McGrane, et al., 2011), and noting that future studies on dairy with different sodium contents were of interest. The role of potassium on blood pressure more generally has been reviewed (Geleijnse, Kok, \& Grobbee, 2003; Whelton et al., 1997), but potassium in the context of dairy as the mechanism of dairy's potential hypotensive effects requires further investigation. The population-based evidence seems consistent with the randomized controlled trial (RCT) evidence with regard to neutral or protective associations between dairy generally and CVD, but more evidence would be valuable on comparing full-fat with reduced- or non-fat dairy (Drouin-Chartier, Brassard, et al., 2016).

Individual factors-With the increasing focus on 'precision' or 'individualized' approaches to diet and health, several important points were discussed about what individual factors might influence effects and associations between dairy and CVD, and who, if anyone, should receive advice to restrict consumption of full-fat dairy (NG11, Figure 6). General questions about whether recommendations should differ between men and women; whether saturated fat (particularly from dairy) should be a concern for older individuals; and whether lactose intolerance influenced any difference in the dairy recommendations were briefly discussed, with no immediate resolution from the panel. Two historical lines of evidence were briefly discussed. The evolution of lactase persistence in humans was mentioned as evidence of the incorporation of dairy into some diets over the span of millennia. On the other hand, the ecological experience of Finland over the last half century 
was discussed, in which a public health campaign discouraged smoking and the consumption of full-fat dairy, butter, and fatty meats to target CVD risk factors. Indeed, fullfat dairy, CVD, and its risk factors decreased, but so too did smoking along with other substantial changes. At least one panelist indicated that the Finnish experience may indicate that too much dairy may impair health, while the panel generally noted that edge cases of extreme intakes and evolutionary evidence were difficult to interpret with respect to the relation between dairy and CVD.

However, several panelists suggested that it may be prudent for people who are at high risk of CVD to avoid full-fat dairy (see Prudent Recommendations). This suggestion spurred two different discussions: 1) how one defines high risk, and 2) whether dairy may be replacing 'worse' dietary choices. For the former, "high risk" was proposed to be consistent with the Pooled Cohort Equation (Goff et al., 2014). Given the robust conversation around LDL-C from earlier, it was noted that LDL-C is not directly included as part of the equation, though HDL-C and total cholesterol are both included. The utility of the equation was questioned for studying the effects of dairy on LDL-C as a specific risk factor that is absent from the definition of "high risk", though LDL-C is indirectly included through co-linearity with HDL-C and total cholesterol. As for replacing 'worse' dietary choices, the limitations of substitution study methods for modeling replacement of foods in the diet (discussed above) imply that, although this is a potentially promising hypothesis, the panel felt evidence of such substitutions occurring in practice was equivocal.

Other putative causal pathways-Several emerging or evolving areas of research, particularly as they relate to dairy, were mentioned as potential mediators between dairy and CVD risk (NG4, Figure 7): signaling from microRNAs, alterations of the gut microbiome, and pro/anti-inflammatory effects of dairy or dairy components. Influences of dairy on microRNAs or the gut microbiome were generally felt to have insufficient evidence at present, particularly when considering whether they are on the pathway between dairy and CVD risk. On the other hand, the panel generally agreed that dairy either had a neutral or anti-inflammatory effect, as evidenced by a summary of nutrition RCTs (Labonte, et al., 2013). Although atherosclerosis is considered a disease of lipid accumulation and inflammation, it is presently unclear whether such potential anti-inflammatory effects are on the causal pathway between dairy and changes in CVD risk, and, if so, whether dairy product consumption has clinically relevant anti-inflammatory effects.

Other effects of specific nutrients or dairy foods-Differences among specific dairy foods or specific nutrients in dairy foods were also discussed, but many were brought up in passing (NG10, Figure 8). Subclasses of macronutrients were specifically of interest, in addition to dairy fat itself. Dietary fat was discussed in the context of full-fat dairy in that dietary fats are commonly thought to be satiating, consistent with the discussion in the obesity section. However, discussions of specific lipids or lipid classes regarding satiety were less clear. The potential for effects of saturated fats and unique milk lipids on appetite were discussed in the context of LDL-C and obesity above. The potential for medium-chain triglycerides to mitigate CVD was brought up as a question that warrants further investigation, particularly in the context of the complex dairy lipid profile. Butyrate is a 
short-chain fatty acid found in dairy products. It has historically been of interest in the potential health-promoting effects of dairy, but with the broader interest in gut microbial research has been considered anew with respect to volatile fatty acids generated by gut fermentation. The discussion of butyrate also was left with uncertainty as to its causal pathway to CVD risk. Dietary protein was discussed in terms of appetite and general health promotion, but also with respect to peptides that might alter insulin secretion or affect blood pressure by acting as angiotensin converting enzyme inhibitors (Labonte, et al., 2013). Thus, dairy protein may uniquely tie into the discussion of diabetes or hypertension as putatively beneficially interacting on the causal pathway to CVD risk. Finally, minerals were briefly discussed again, both in the context of hypertension, as well as for the potential for calcium to result in fatty acid excretion. There is some mechanistic evidence for the latter (Soerensen, Thorning, Astrup, Kristensen, \& Lorenzen, 2014), but the conclusions about the influence of this mechanism either for energy balance or CVD are limited (Booth, et al., 2015).

Proposition 2C: We don't have enough evidence-Early in the discussion, panelists suggested a third proposition, "We don't have enough evidence," and over the course of the day this area of discussion was filled out more robustly (NG12, Figure 9). Throughout the topic areas already discussed herein, most of the discussion of limitations revolved around evidence connecting dairy to a mediator or connecting the mediator to CVD risk. However, Proposition $\mathrm{C}$ revolved more around the link from dairy to CVD, both inclusive and exclusive of the mediators. The discussions revolved around questions of quality of evidence in determining causal effects in nutrition research.

First, the quality of evidence on population dairy consumption was questioned. Notably, most large-scale analyses use self-reported intake data, the strengths and limitations of which have been described thoroughly elsewhere [c.f., (Dhurandhar et al., 2015; Subar et al., 2015)]. In addition to the typical limitations of self-report, specific concerns were discussed about dairy foods (Magarey, et al., 2015). For instance, some questionnaires have not distinguished amongst full-, reduced-, or non-fat dairy (Mente, et al., 2009). The mineral content of various dairy products may differ, and coarse questionnaires may not distinguish amongst, for example, high versus low sodium cheeses. This concern is further compounded by 'substitution studies,' in which researchers try to estimate the replacement of one food or nutrient with another. If the information on the foods or nutrients are unclear, then so, too, will be the substitution. Further, nutrients are part of foods that may, in turn, be used as ingredients. As an example, simulating the replacement of saturated fats from dairy would require the substitution model to also account for the alteration of the unique composition of bioavailable nutrients in dairy that accompany the dairy fat, the dairy product in toto, or potentially even the entire dish. Thus, it is difficult to interpret what associations between self-reported dairy consumption and CVD risk are actually comparing, whether through ordinary or substitution analyses. The use of biomarkers of dairy consumption to resolve some of these challenges was noted as a developing tool to investigate dairy consumption, but the limited number and low use of biomarkers in research was seen as a limitation that needs to be addressed. 
Second, much of the literature on CVD risk comes from ordinary association tests of observational evidence -- which are known to provide lower quality evidence for causal reasoning -- or shorter-term RCT evidence on intermediate endpoints -- which can give stronger causal evidence but not on the outcome of interest. Much has been written about limitations of ordinary association tests in general, but for dairy and CVD (and nutrition in general) there is substantial potential for confounding unaccounted for in models to explain the typically small associations. A proposed example of this was asked: Are dietary choices in general just proxies for socio-economic status? If so, it would make accounting for such factors in analyses challenging. Meta-analytic evidence, including meta-analyses of metaanalyses (so called 'meta-meta-analyses), also have unique challenges in nutrition research, necessitating the review of the original studies for confirmation of key details to adequately characterize which outcomes are being compared and how, as well as which exact foods were tested. Issues with meta-analytic evidence, particularly in nutrition research, have been discussed elsewhere [c.f., (Barnard, Willett, \& Ding, 2017)]. The panel highlighted the need for stronger evidence, and for analyses to be conducted within the causal inference continuum from RCTs to ordinary association tests.

We emphasize that these questions and limitations apply regardless of direction of the evidence. Whether an association or effect is negative, null, or positive with respect to dairy, the strength of evidence of an effect in many cases is limited. Conversely, just because the data are limited should not be grounds to conclude there is no effect; rather, the strength of conclusions drawn from the evidence should be commensurate with the strength of the evidence.

\section{Prudent recommendation?}

All scientific work is incomplete whether it be observational or experimental. All scientific work is liable to be upset or modified by advancing knowledge. That does not confer upon us a freedom to ignore the knowledge we already have, or to postpone the action that it appears to demand at a given time.

- Sir Austin Bradford Hill (Hill, 1965)

The theme of uncertainty that permeated much of the discussion led to a question posed at the end of the session with respect to full-fat dairy: "Is there a recommendation based on prudent action as opposed to scientific consensus?" (NG13, Figure 10) The responses tended towards two directions. One was to focus first on the individual receiving the recommendation. Several panelists suggested that full-fat dairy is a concern for those in the high-risk category, predominantly because of the prevailing concerns about saturated fat [c.f., (Sacks et al., 2017)]. The other was a general recommendation of 'moderation,' such as $2-3$ servings per day if the consumer enjoys dairy and has no other contraindications.

\section{Limitations and lessons learned}

\section{Limitations}

There are at least three important considerations for interpreting this document. First, one of the most valuable parts of this process is clarifying what experts mean when they agree or 
disagree, rather than the dichotomous platitudes that are frequently communicated about foods being 'good' or 'bad.' Statements about the health effects of dairy presented herein represent evidence-informed and evidence-refined expert opinions. We do not present this document as a systematic evaluation of all evidence, even when we draw upon systematic reviews and meta-analyses to support or refute particular propositions. Indeed, during the peer review of this manuscript, a reviewer remarked that there was too little attention to some topics, such as the potential anti-inflammatory role of dairy [as reviewed by (Lordan, Tsoupras, Mitra, \& Zabetakis, 2018)] or the influence of the dairy food matrix [as reviewed by (Thorning, et al., 2017)]. As the reviewer noted, the discussions in dialogue mapping are shaped by the expertise of the panelists, the materials provided to stimulate the dialogue, and familiarity with the vast literature on the topic.

Second, this is not a consensus document. In fact, one of the values of this document is explicitly pointing out where disagreements occur because scientific disagreement and skepticism discussed in good faith are essential to refining knowledge (Allison, et al., 2018). In preparing this document, panelists were asked to confirm whether, to the best of their recollection, the presentation of information herein represents what was discussed, not whether they concur that the conclusions are ultimately correct. Unresolved disagreements have been presented throughout.

Third, the panelists and attendees were employed in the United States and Canada. Although we considered research from around the world, it is possible that additional perspectives and expertise from other countries, contexts, and cultures may have resulted in different interpretations, concerns, or nuances.

\section{Procedural lessons}

Three main lessons arose from the way that Phase 2 was executed. The first is the use of two contradicting propositions. Because of the way dialogue mapping categorizes nodes as issues/questions, ideas, or pro/con arguments, a single proposition would have sufficed to stimulate the meeting. Statements agreeing with or refuting the core proposition would then arise out of a single node. In earlier versions of the map, points refuting proposition $2 \mathrm{~B}$ were also shown as supporting proposition $2 \mathrm{~A}$ because of the contradictory format. Future dialogue mapping efforts for scientific questions may benefit from presenting a single, core proposition to prevent this fracturing of the map.

The second is the use of separate people in the roles of Map Facilitator and Scientific Facilitator. We found this division of roles to be beneficial in that each could focus on their expertise. However, we recommend in the future that a Scientific Facilitator become more familiar with the dialogue mapping process to know when to pause to reinforce the points as presented on the map, and the Map Facilitator to become more familiar with the science to better be able to recognize how statements made with scientific vernacular are related. This synergy would help make a stronger, clearer, and immediately organized map that contains a deeper and more coherent summary of the science, decreasing the need for post-meeting map refinement as required in Phase 3 herein.

Crit Rev Food Sci Nutr. Author manuscript; available in PMC 2022 January 01. 
Third, the map of the discussion represents what might be called an "immature map," in that the panel did not reach the final goal of consensus or clearly articulated disagreement for each of the lines of discussion. This result is in part due to the expansive collection of dairy foods, nutrients within dairy foods, and the complexities of nutrition research that resulted in the discussion branching into numerous directions. Indeed, as we were preparing this manuscript, authors suggested additional points to consider to add to the map, such as the importance of life-cycle stage (e.g., adolescents, pregnant women). Much more could have been discussed, and resolving each terminal node would be a massive undertaking beyond what could be accomplished in one sitting. Herein, we tried to remain faithful to what we discussed in our mapping session and to share our experiences for others who may wish to use a dialogue mapping approach. We present below some recommendations for future directions of research that were either implied or explicitly identified during the panel.

\section{Recommendations and Conclusions}

In response to the spontaneously created Proposition 2C, "We don't have enough evidence," a question was posed to the panelists: "What further studies are needed?" (NG12) Suggestions were given by panelists for research that either has not been done at all, or that has not been done to a sufficient extent as to make firm conclusions, including:

- Formally investigate the effects of full-fat versus reduced- or low-fat versus nonfat dairy products in direct causal linkages. Relatively few studies have compared the different types of dairy head-to-head, particularly with respect to disease (as opposed to intermediate or biomarker) endpoints. Testing these effects for specific kinds of dairy products, such as full- or low-fat yogurt, was also discussed.

- $\quad$ Conduct more hard endpoint studies on full-fat dairy and blood pressure, including studying cheeses lower in sodium.

- Investigate dairy in relation to the microbiome, as well as volatile fatty acids such as butyrate that are both a natural component of milk and a product of gut microbial fermentation.

- $\quad$ Study isocaloric versus ad libitum intake. There was particular interest in what happens to the rest of the diet when dairy, particularly full-fat dairy, is introduced, increased, or decreased. Furthermore, what is the effect of dairy on a background of different kinds of diets (e.g., introduction of dairy into an otherwise Mediterranean-type pattern)? One approach is to mine databases for a better prediction of these tradeoffs when types of dairy are substituted, or when dairy is added or removed altogether; however, the panel generally expressed that such studies were often limited by self-reported intake.

- Test whether consumption across the day changes the effects of dairy. Chronobiology is increasingly of interest, and the types and timing of dairy foods' effects may vary across the day, whether because of the unique combination of nutrients found in dairy, broad classes of nutrients (e.g., interest 
in high-protein breakfasts), or individual variation in metabolic and absorptive functions.

- Develop better biomarkers and measurements of intake of dairy. Some biomarkers have been investigated for a variety of dairy foods and dairy components, but they have been insufficiently validated. Each potential biomarker has outstanding questions with respect to their specificity, reliability, sample stability, analytical variability, or other aspects of validation (Munger et al., 2018).

\section{Supplementary Material}

Refer to Web version on PubMed Central for supplementary material.

\section{Acknowledgments}

As a condition of participating in this project, all investigators and panelists agreed to either be acknowledged by name or serve as a co-author. All co-authors have expressed an interest in being listed as a co-author and met standard authorship guidelines. We also acknowledge the contributions of Drs. Victor Fulgoni, Peter Jones, Benoit Lamarche, and Theresa Nicklas. Preliminary results were presented at the Nutrition 2019 meeting (A. Brown, Kaiser, Keitt, \& Allison, 2019).

Declaration of interest statement

The following is current as of the initial submission of this manuscript. Brown: In the last twelve months, Dr. Brown has received travel expenses from University of Louisville; speaking fees from Kentuckiana Health Collaborative, and Rippe Lifestyle Institute, Inc.; and he has been involved in research for which his institution or colleagues have received grants from Dairy Management, Inc., NIH, and the Sloan Foundation. Fontaine: In the last 3 years, Dr. Fontaine served on the scientific advisory board to Virta Health Corp and has stock options. He also serves on the scientific advisory board to Atkins Nutritionals, and has been involved in research for which his institution or colleagues have received grants from Dairy Management, Inc. Gibson: In the last 12 months, Mrs. Gibson has received travel expenses from TriNetX and support from NIH. Bier: In the last 3 years, Dr. Bier discloses travel, speaking, or advisory fees from International Life Sciences Institute; International Council on Amino Acid Science; Nutrition and Growth Solutions, Inc.; Ajinomoto, Co.; Lorenzini Foundation; CrossFit Foundation; International Glutamate Technical Committee; Nestle; Indiana University Bloomington; Mallinckrodt Pharmaceuticals; Soremartec/Ferrero Co.; International Council on Amino Acid Science (ICAAS); Infant Nutrition Council of America; Nutrition \& Growth Solutions; and The Israel Institute. Jacobs: Consultant to the California Walnut Commission. Kris-Etherton: Serves on the scientific advisory board to HumanN and Seafood Nutrition Partnership, and has held research grants with CA Walnut Commission, CA Strawberry Commission, Ocean Spray Cranberries, McCormick Science Institute, Hass Avocado Board, Alliance for Potato Research, The Peanut Institute, American Pistachio Growers, and ACH Foods. Maki: In the past 3 years - advisory boards for National Dairy Council and Beef Checkoff, research funding for General Mills, Kellogg, Beef Checkoff, Almond Board of California, ACH Foods. Teran-Garcia: USDA support and co-Investigator in a project sponsored by the Dairy Research Institute. Allison: Dr. Allison reports grants from NIH, outside the submitted work; and Dr. Allison has received personal payments or promises for same from: American Society for Nutrition; American Statistical Association; Biofortis; Columbia University; Fish \& Richardson, P.C.; Frontiers Publishing; Henry Stewart Talks; IKEA; Indiana University; Laura and John Arnold Foundation; Johns Hopkins University; Law Offices of Ronald Marron; MD Anderson Cancer Center; Medical College of Wisconsin; National Institutes of Health (NIH); Sage Publishing; The Obesity Society; Tomasik, Kotin \& Kasserman LLC; University of Alabama at Birmingham; University of Miami; Nestle; WW (formerly Weight Watchers International, LLC); California Walnut Commission. Donations to a foundation have been made on his behalf by the Northarvest Bean Growers Association. Dr. Allison is an unpaid member of the International Life Sciences Institute North America Board of Trustees. Dr. Allison's institution, Indiana University, has received funds to support his research or educational activities from: NIH; Alliance for Potato Research and Education; American Federation for Aging Research; Dairy Management Inc; Herbalife; Laura and John Arnold Foundation; Oxford University Press. Kaiser, Keitt, Gower, Shikany, Vorland, Beitz, Brenna, Miller, and St-Onge: Nothing further to disclose beyond participating in this project funded by Dairy Management Inc. 


\section{References}

Alexander DD, Bylsma LC, Vargas AJ, Cohen SS, Doucette A, Mohamed M, Fryzek JP (2016). Dairy consumption and CVD: a systematic review and meta-analysis. Br J Nutr, 115(4), pp. 737-750. doi:10.1017/S0007114515005000 Retrieved from 10.1017/S0007114515005000https:// www.ncbi.nlm.nih.gov/pubmed/26786887 Retrieved from https://www.ncbi.nlm.nih.gov/pubmed/ 26786887 [PubMed: 26786887]

Allison DB, Pavela G, \& Oransky I (2018). Reasonable Versus Unreasonable Doubt. American Scientist, 106(2), pp. 84-87. Retrieved from <Go to ISI>://WOS:000426537100011

Aune D, Norat T, Romundstad P, \& Vatten LJ (2013). Dairy products and the risk of type 2 diabetes: a systematic review and dose-response meta-analysis of cohort studies. Am J Clin Nutr, 98(4), pp. 1066-1083. doi:10.3945/ajcn.113.059030 Retrieved from 10.3945/ajcn.113.059030https:// www.ncbi.nlm.nih.gov/pubmed/23945722 Retrieved from https://www.ncbi.nlm.nih.gov/pubmed/ 23945722 [PubMed: 23945722]

Babio N, Becerra-Tomas N, Martinez-Gonzalez MA, Corella D, Estruch R, Ros E, Investigators, P. (2015). Consumption of Yogurt, Low-Fat Milk, and Other Low-Fat Dairy Products Is Associated with Lower Risk of Metabolic Syndrome Incidence in an Elderly Mediterranean Population. J Nutr, 145(10), pp. 2308-2316. doi:10.3945/jn.115.214593 Retrieved from 10.3945/jn.115.214593https:// www.ncbi.nlm.nih.gov/pubmed/26290009 Retrieved from https://www.ncbi.nlm.nih.gov/pubmed/ 26290009 [PubMed: 26290009]

Barnard ND, Willett WC, \& Ding EL (2017). The Misuse of Meta-analysis in Nutrition ResearchMisuse of Meta-analysis in Nutrition ResearchMisuse of Meta-analysis in Nutrition Research. Jama, 318(15), pp. 1435-1436. doi:10.1001/jama.2017.12083 Retrieved from 10.1001/ jama.2017.12083https://doi.org/10.1001/jama.2017.12083 Retrieved from https://doi.org/10.1001/ jama.2017.12083 [PubMed: 28975260]

Booth AO, Huggins CE, Wattanapenpaiboon N, \& Nowson CA (2015). Effect of increasing dietary calcium through supplements and dairy food on body weight and body composition: a meta-analysis of randomised controlled trials. British Journal of Nutrition, 114(7), pp. 1013-1025. doi:10.1017/ S0007114515001518 Retrieved from 10.1017/S0007114515001518https://www.cambridge.org/ core/article/effect-of-increasing-dietary-calcium-through-supplements-and-dairy-food-on-bodyweight-and-body-composition-a-metaanalysis-of-randomised-controlled-trials/ 3F57D60E445C26983D94CD313FDBB9F9 Retrieved from https://www.cambridge.org/core/ article/effect-of-increasing-dietary-calcium-through-supplements-and-dairy-food-on-body-weightand-body-composition-a-metaanalysis-of-randomised-controlled-trials/ 3F57D60E445C26983D94CD313FDBB9F9

Bordoni A, Danesi F, Dardevet D, Dupont D, Fernandez AS, Gille D, Vergeres G (2017). Dairy products and inflammation: A review of the clinical evidence. Crit Rev Food Sci Nutr, 57(12), pp. 2497-2525. doi:10.1080/10408398.2014.967385 Retrieved from 10.1080/10408398.2014.967385https://www.ncbi.nlm.nih.gov/pubmed/26287637 Retrieved from https://www.ncbi.nlm.nih.gov/pubmed/26287637 [PubMed: 26287637]

Brown A, Kaiser K, Keitt A, \& Allison D (2019). Science Dialogue Mapping of Knowledge and Knowledge Gaps Related to the Effects of Dairy Intake on Human Cardiovascular Disease (P13002-19). Curr Dev Nutr, 3(Suppl 1)doi:10.1093/cdn/nzz036.P13-002-19 Retrieved from 10.1093/cdn/nzz036.P13-002-19https://www.ncbi.nlm.nih.gov/pubmed/31225144 Retrieved from https://www.ncbi.nlm.nih.gov/pubmed/31225144

Brown AW, Trenkle AH, \& Beitz DC (2011). Diets high in conjugated linoleic acid from pasture-fed cattle did not alter markers of health in young women. Nutrition Research, 31(1), pp. 33-41. doi:10.1016/j.nutres.2010.12.003 Retrieved from http://www.sciencedirect.com/science/article/pii/ S0271531710002617 [PubMed: 21310304]

Chen M, Pan A, Malik VS, \& Hu FB (2012). Effects of dairy intake on body weight and fat: a metaanalysis of randomized controlled trials. Am J Clin Nutr, 96(4), pp. 735-747. doi:10.3945/ ajcn.112.037119 Retrieved from 10.3945/ajcn.112.037119https://www.ncbi.nlm.nih.gov/pubmed/ 22932282 Retrieved from https://www.ncbi.nlm.nih.gov/pubmed/22932282 [PubMed: 22932282]

Conklin J (2005). Dialogue Mapping: Building Shared Understanding of Wicked Problems: John Wiley \& Sons, Inc. 
Crichton GE, Bryan J, Buckley J, \& Murphy KJ (2011). Dairy consumption and metabolic syndrome: a systematic review of findings and methodological issues. Obes Rev, 12(5), pp. e190-201. doi:10.1111/j.1467-789X.2010.00837.x Retrieved from 10.1111/j.1467-789X.2010.00837.xhttps:// www.ncbi.nlm.nih.gov/pubmed/21348924 Retrieved from https://www.ncbi.nlm.nih.gov/pubmed/ 21348924 [PubMed: 21348924]

de Goede J, Geleijnse JM, Ding EL, \& Soedamah-Muthu SS (2015). Effect of cheese consumption on blood lipids: a systematic review and meta-analysis of randomized controlled trials. Nutr Rev, 73(5), pp. 259-275. doi:10.1093/nutrit/nuu060 Retrieved from 10.1093/nutrit/nuu060https:// www.ncbi.nlm.nih.gov/pubmed/26011901 Retrieved from https://www.ncbi.nlm.nih.gov/pubmed/ 26011901 [PubMed: 26011901]

de Goede J, Soedamah-Muthu SS, Pan A, Gijsbers L, \& Geleijnse JM (2016). Dairy Consumption and Risk of Stroke: A Systematic Review and Updated Dose-Response Meta-Analysis of Prospective Cohort Studies. J Am Heart Assoc, 5(5)doi:10.1161/JAHA.115.002787 Retrieved from 10.1161/ JAHA.115.002787https://www.ncbi.nlm.nih.gov/pubmed/27207960 Retrieved from https:// www.ncbi.nlm.nih.gov/pubmed/27207960

Derkach A, Sampson J, Joseph J, Playdon MC, \& Stolzenberg-Solomon RZ (2017). Effects of dietary sodium on metabolites: the Dietary Approaches to Stop Hypertension (DASH)-Sodium Feeding Study. Am J Clin Nutr, 106(4), pp. 1131-1141. doi:10.3945/ajcn.116.150136 [PubMed: 28855223]

Dhurandhar NV, Schoeller D, Brown AW, Heymsfield SB, Thomas D, Sorensen TI, Energy Balance Measurement Working, G. (2015). Energy balance measurement: when something is not better than nothing. International Journal of Obesity, 39(7), pp. 1109-1113. doi:10.1038/ijo.2014.199 Retrieved from 10.1038/ijo.2014.199https://www.ncbi.nlm.nih.gov/pubmed/25394308 Retrieved from https://www.ncbi.nlm.nih.gov/pubmed/25394308 [PubMed: 25394308]

Ding M, Huang T, Bergholdt HK, Nordestgaard BG, Ellervik C, Qi L, \& Consortium C (2017). Dairy consumption, systolic blood pressure, and risk of hypertension: Mendelian randomization study. BMJ, 356, p j1000. doi:10.1136/bmj.j1000 Retrieved from 10.1136/bmj.j1000https:// www.ncbi.nlm.nih.gov/pubmed/28302601 Retrieved from https://www.ncbi.nlm.nih.gov/pubmed/ 28302601 [PubMed: 28302601]

Drouin-Chartier JP, Brassard D, Tessier-Grenier M, Cote JA, Labonte ME, Desroches S, Lamarche B (2016). Systematic Review of the Association between Dairy Product Consumption and Risk of Cardiovascular-Related Clinical Outcomes. Adv Nutr, 7(6), pp. 1026-1040. doi:10.3945/ an.115.011403 Retrieved from 10.3945/an.115.011403https://www.ncbi.nlm.nih.gov/pubmed/ 28140321 Retrieved from https://www.ncbi.nlm.nih.gov/pubmed/28140321 [PubMed: 28140321]

Drouin-Chartier JP, Cote JA, Labonte ME, Brassard D, Tessier-Grenier M, Desroches S, Lamarche B (2016). Comprehensive Review of the Impact of Dairy Foods and Dairy Fat on Cardiometabolic Risk. Adv Nutr, 7(6), pp. 1041-1051. doi:10.3945/an.115.011619 [PubMed: 28140322]

Dumas AA, Lapointe A, Dugrenier M, Provencher V, Lamarche B, \& Desroches S (2017). A systematic review of the effect of yogurt consumption on chronic diseases risk markers in adults. Eur J Nutr, 56(4), pp. 1375-1392. doi:10.1007/s00394-016-1341-7 Retrieved from 10.1007/ s00394-016-1341-7https://www.ncbi.nlm.nih.gov/pubmed/27807623 Retrieved from https:// www.ncbi.nlm.nih.gov/pubmed/27807623 [PubMed: 27807623]

Geleijnse JM, Kok FJ, \& Grobbee DE (2003). Blood pressure response to changes in sodium and potassium intake: a metaregression analysis of randomised trials. J Hum Hypertens, 17(7), pp. 471-480. doi:10.1038/sj.jhh.1001575 Retrieved from 10.1038/sj.jhh.1001575https://doi.org/ 10.1038/sj.jhh.1001575 Retrieved from https://doi.org/10.1038/sj.jhh.1001575 [PubMed: 12821954]

Geng T, Qi L, \& Huang T (2017). Effects of Dairy Products Consumption on Body Weight and Body Composition Among Adults: An Updated Meta-Analysis of 37 Randomized Control Trials. Mol Nutr Food Resdoi:10.1002/mnfr.201700410 Retrieved from 10.1002/mnfr.201700410https:// www.ncbi.nlm.nih.gov/pubmed/29058378 Retrieved from https://www.ncbi.nlm.nih.gov/pubmed/ 29058378

Gibson RA, Makrides M, Smithers LG, Voevodin M, \& Sinclair AJ (2009). The effect of dairy foods on CHD: a systematic review of prospective cohort studies. Br J Nutr, 102(9), pp. 1267-1275. doi:10.1017/S0007114509371664 Retrieved from 10.1017/S0007114509371664https:// 
www.ncbi.nlm.nih.gov/pubmed/19682399 Retrieved from https://www.ncbi.nlm.nih.gov/pubmed/ 19682399 [PubMed: 19682399]

Gil A, \& Ortega RM (2019). Introduction and Executive Summary of the Supplement, Role of Milk and Dairy Products in Health and Prevention of Noncommunicable Chronic Diseases: A Series of Systematic Reviews. Adv Nutr, 10(suppl_2), pp. S67-s73. doi:10.1093/advances/nmz020 [PubMed: 31089742]

Goff DC, Lloyd-Jones DM, Bennett G, Coady S, D’Agostino RB, Gibbons R, Wilson PWF (2014). 2013 ACC/AHA Guideline on the Assessment of Cardiovascular Risk. Circulation, 129(25_suppl_2), pp. S49-S73. doi:doi:10.1161/01.cir.0000437741.48606.98 Retrieved from 10.1161/01.cir.0000437741.48606.98https://www.ahajournals.org/doi/abs/ 10.1161/01.cir.0000437741.48606.98 Retrieved from https://www.ahajournals.org/doi/abs/ 10.1161/01.cir.0000437741.48606.98 [PubMed: 24222018]

Guasch-Ferre M, Becerra-Tomas N, Ruiz-Canela M, Corella D, Schroder H, Estruch R, Salas-Salvado J (2017). Total and subtypes of dietary fat intake and risk of type 2 diabetes mellitus in the Prevencion con Dieta Mediterranea (PREDIMED) study. Am J Clin Nutr, 105(3), pp. 723-735. doi:10.3945/ajcn.116.142034 Retrieved from 10.3945/ajcn.116.142034https:// www.ncbi.nlm.nih.gov/pubmed/28202478 Retrieved from https://www.ncbi.nlm.nih.gov/pubmed/ 28202478 [PubMed: 28202478]

Hill AB (1965). The Environment and Disease: Associaiton or Causation? Proceedings of the Royal Society of Medicine, 58(5), pp. 295-300. Retrieved from https://www.ncbi.nlm.nih.gov/pubmed/ 14283879 [PubMed: 14283879]

Ivey KL, Lewis JR, Hodgson JM, Zhu K, Dhaliwal SS, Thompson PL, \& Prince RL (2011). Association between yogurt, milk, and cheese consumption and common carotid artery intimamedia thickness and cardiovascular disease risk factors in elderly women. Am J Clin Nutr, 94(1), pp. 234-239. doi:10.3945/ajcn.111.014159 Retrieved from 10.3945/ajcn.111.014159https:// www.ncbi.nlm.nih.gov/pubmed/21613553 Retrieved from https://www.ncbi.nlm.nih.gov/pubmed/ 21613553 [PubMed: 21613553]

Key J, Cantarero A, Cohen D, Conn C, \& Cerami J (2016). The Dairy Fat Paradox: A Systematic Review of the Evidence. Topics in Clinical Nutrition, 31(4), pp. 280-295.

Kushi LH, Lenart EB, \& Willett WC (1995). Health implications of Mediterranean diets in light of contemporary knowledge. 1. Plant foods and dairy products. Am J Clin Nutr, 61(6 Suppl), pp. 1407S-1415S. doi:10.1093/ajcn/61.6.1407S Retrieved from 10.1093/ajcn/61.6.1407Shttps:// www.ncbi.nlm.nih.gov/pubmed/7754996 Retrieved from https://www.ncbi.nlm.nih.gov/pubmed/ 7754996 [PubMed: 7754996]

Labonte ME, Couture P, Richard C, Desroches S, \& Lamarche B (2013). Impact of dairy products on biomarkers of inflammation: a systematic review of randomized controlled nutritional intervention studies in overweight and obese adults. Am J Clin Nutr, 97(4), pp. 706-717. doi:10.3945/ ajcn.112.052217 Retrieved from 10.3945/ajcn.112.052217https://www.ncbi.nlm.nih.gov/pubmed/ 23446894 Retrieved from https://www.ncbi.nlm.nih.gov/pubmed/23446894 [PubMed: 23446894]

Larsson SC, Crippa A, Orsini N, Wolk A, \& Michaelsson K (2015). Milk Consumption and Mortality from All Causes, Cardiovascular Disease, and Cancer: A Systematic Review and Meta-Analysis. Nutrients, 7(9), pp. 7749-7763. doi:10.3390/nu7095363 Retrieved from 10.3390/ nu7095363https://www.ncbi.nlm.nih.gov/pubmed/26378576 Retrieved from https:// www.ncbi.nlm.nih.gov/pubmed/26378576 [PubMed: 26378576]

Liang J, Zhou Q, Kwame Amakye W, Su Y, \& Zhang Z (2016). Biomarkers of dairy fat intake and risk of cardiovascular disease: A systematic review and meta analysis of prospective studies. Crit Rev Food Sci Nutr, pp. 1-9. doi:10.1080/10408398.2016.1242114 Retrieved from 10.1080/10408398.2016.1242114https://www.ncbi.nlm.nih.gov/pubmed/28001085 Retrieved from https://www.ncbi.nlm.nih.gov/pubmed/28001085 [PubMed: 24915376]

Lordan R, Tsoupras A, Mitra B, \& Zabetakis I (2018). Dairy Fats and Cardiovascular Disease: Do We Really Need to Be Concerned? Foods, 7(3), p 29 Retrieved from https://www.mdpi.com/ 2304-8158/7/3/29

Ludwig DS, \& Willett WC (2013). Three daily servings of reduced-fat milk: an evidence-based recommendation? JAMA Pediatr, 167(9), pp. 788-789. doi:10.1001/jamapediatrics.2013.2408 
Retrieved from 10.1001/jamapediatrics.2013.2408https://www.ncbi.nlm.nih.gov/pubmed/ 23818041 Retrieved from https://www.ncbi.nlm.nih.gov/pubmed/23818041 [PubMed: 23818041]

Machin DR, Park W, Alkatan M, Mouton M, \& Tanaka H (2014). Hypotensive effects of solitary addition of conventional nonfat dairy products to the routine diet: a randomized controlled trial. Am J Clin Nutr, 100(1), pp. 80-87. doi:10.3945/ajcn.114.085761 [PubMed: 24808486]

Machin DR, Park W, Alkatan M, Mouton M, \& Tanaka H (2015). Effects of non-fat dairy products added to the routine diet on vascular function: a randomized controlled crossover trial. Nutr Metab Cardiovasc Dis, 25(4), pp. 364-369. doi:10.1016/j.numecd.2015.01.005 [PubMed: 25770758]

Magarey A, Baulderstone L, Yaxley A, Markow K, \& Miller M (2015). Evaluation of tools used to measure calcium and/or dairy consumption in adults. Public Health Nutr, 18(7), pp. 1225-1236. doi:10.1017/s1368980014001633 Retrieved from 10.1017/s1368980014001633https:// www.cambridge.org/core/services/aop-cambridge-core/content/view/ EFA92C3EE9C2B95C8F6C328D21ABE919/S1368980014001633a.pdf/div-class-title-evaluationof-tools-used-to-measure-calcium-and-or-dairy-consumption-in-adults-div.pdf Retrieved from https://www.cambridge.org/core/services/aop-cambridge-core/content/view/

EFA92C3EE9C2B95C8F6C328D21ABE919/S1368980014001633a.pdf/div-class-title-evaluationof-tools-used-to-measure-calcium-and-or-dairy-consumption-in-adults-div.pdf [PubMed: 25171323]

McGrane MM, Essery E, Obbagy J, Lyon J, Macneil P, Spahn J, \& Van Horn L (2011). Dairy Consumption, Blood Pressure, and Risk of Hypertension: An Evidence-Based Review of Recent Literature. Curr Cardiovasc Risk Rep, 5(4), pp. 287-298. doi:10.1007/s12170-011-0181-5 Retrieved from 10.1007/s12170-011-0181-5https://www.ncbi.nlm.nih.gov/pubmed/22384284 Retrieved from https://www.ncbi.nlm.nih.gov/pubmed/22384284 [PubMed: 22384284]

Menotti A, Kromhout D, Blackburn H, Fidanza F, Buzina R, \& Nissinen A (1999). Food intake patterns and 25-year mortality from coronary heart disease: cross-cultural correlations in the Seven Countries Study. The Seven Countries Study Research Group. Eur J Epidemiol, 15(6), pp. 507515. Retrieved from https://www.ncbi.nlm.nih.gov/pubmed/10485342 [PubMed: 10485342]

Mente A, de Koning L, Shannon HS, \& Anand SS (2009). A systematic review of the evidence supporting a causal link between dietary factors and coronary heart disease. Arch Intern Med, 169(7), pp. 659-669. doi:10.1001/archinternmed.2009.38 Retrieved from 10.1001/ archinternmed.2009.38https://www.ncbi.nlm.nih.gov/pubmed/19364995 Retrieved from https:// www.ncbi.nlm.nih.gov/pubmed/19364995 [PubMed: 19364995]

Mikkila V, Rasanen L, Laaksonen MM, Juonala M, Viikari J, Pietinen P, \& Raitakari OT (2009). Longterm dietary patterns and carotid artery intima media thickness: the Cardiovascular Risk in Young Finns Study. Br J Nutr, 102(10), pp. 1507-1512. doi:10.1017/S000711450999064X Retrieved from 10.1017/S000711450999064Xhttps://www.ncbi.nlm.nih.gov/pubmed/19811695 Retrieved from https://www.ncbi.nlm.nih.gov/pubmed/19811695 [PubMed: 19811695]

Mozaffarian D, Hao T, Rimm EB, Willett WC, \& Hu FB (2011). Changes in Diet and Lifestyle and Long-Term Weight Gain in Women and Men. New England Journal of Medicine, 364(25), pp. 2392-2404. doi:10.1056/NEJMoa1014296 Retrieved from 10.1056/NEJMoa1014296https:// www.nejm.org/doi/full/10.1056/NEJMoa1014296 Retrieved from https://www.nejm.org/doi/full/ 10.1056/NEJMoa1014296

Mullie P, Pizot C, \& Autier P (2016). Daily milk consumption and all-cause mortality, coronary heart disease and stroke: a systematic review and meta-analysis of observational cohort studies. BMC Public Health, 16(1), p 1236. doi:10.1186/s12889-016-3889-9 Retrieved from 10.1186/ s12889-016-3889-9https://www.ncbi.nlm.nih.gov/pubmed/27927192 Retrieved from https:// www.ncbi.nlm.nih.gov/pubmed/27927192 [PubMed: 27927192]

Munger LH, Garcia-Aloy M, Vazquez-Fresno R, Gille D, Rosana ARR, Passerini A, Pratico G (2018). Biomarker of food intake for assessing the consumption of dairy and egg products. Genes Nutr, 13, p 26. doi:10.1186/s12263-018-0615-5 [PubMed: 30279743]

Ndanuko RN, Tapsell LC, Charlton KE, Neale EP, \& Batterham MJ (2016). Dietary Patterns and Blood Pressure in Adults: A Systematic Review and Meta-Analysis of Randomized Controlled Trials. Adv Nutr, 7(1), pp. 76-89. doi:10.3945/an.115.009753 Retrieved from 10.3945/ an.115.009753https://www.ncbi.nlm.nih.gov/pubmed/26773016 Retrieved from https:// www.ncbi.nlm.nih.gov/pubmed/26773016 [PubMed: 26773016] 
Nicklas TA, O’Neil CE, \& Fulgoni VL 3rd. (2015). Differing statistical approaches affect the relation between egg consumption, adiposity, and cardiovascular risk factors in adults. J Nutr, 145(1), pp. 170S-176S. doi:10.3945/jn.114.194068 Retrieved from 10.3945/jn.114.194068https:// www.ncbi.nlm.nih.gov/pubmed/25527676 Retrieved from https://www.ncbi.nlm.nih.gov/pubmed/ 25527676 [PubMed: 25527676]

Pasin G, \& Comerford KB (2015). Dairy foods and dairy proteins in the management of type 2 diabetes: a systematic review of the clinical evidence. Adv Nutr, 6(3), pp. 245-259. doi:10.3945/ an.114.007690 Retrieved from 10.3945/an.114.007690https://www.ncbi.nlm.nih.gov/pubmed/ 25979490 Retrieved from https://www.ncbi.nlm.nih.gov/pubmed/25979490 [PubMed: 25979490]

Petersen KS, Clifton PM, Blanch N, \& Keogh JB (2015). Effect of improving dietary quality on carotid intima media thickness in subjects with type 1 and type 2 diabetes: a 12-mo randomized controlled trial. Am J Clin Nutr, 102(4), pp. 771-779. doi:10.3945/ajcn.115.112151 Retrieved from 10.3945/ajcn.115.112151https://www.ncbi.nlm.nih.gov/pubmed/26354542 Retrieved from https://www.ncbi.nlm.nih.gov/pubmed/26354542 [PubMed: 26354542]

Phillips SM, \& Zemel MB (2011). Effect of protein, dairy components and energy balance in optimizing body composition. Nestle Nutr Inst Workshop Ser, 69, pp. 97-108; discussion 108113. doi:10.1159/000329288 [PubMed: 22301838]

Pimpin L, Wu JH, Haskelberg H, Del Gobbo L, \& Mozaffarian D (2016). Is Butter Back? A Systematic Review and Meta-Analysis of Butter Consumption and Risk of Cardiovascular Disease, Diabetes, and Total Mortality. PLoS One, 11(6), p e0158118. doi:10.1371/ journal.pone.0158118 Retrieved from 10.1371/journal.pone.0158118https:// www.ncbi.nlm.nih.gov/pubmed/27355649 Retrieved from https://www.ncbi.nlm.nih.gov/pubmed/ 27355649 [PubMed: 27355649]

Prevention;, C. f. D. C. a. (2012). Lifestyle Coach Training Guide: Eat well to prevent T2D. Retrieved Date Accessed, 2019 from https://www.cdc.gov/diabetes/prevention/pdf/t2/CoachModule-4_Eat_Well_to_Prevent_T2.pdf.

Ralston RA, Lee JH, Truby H, Palermo CE, \& Walker KZ (2012). A systematic review and metaanalysis of elevated blood pressure and consumption of dairy foods. J Hum Hypertens, 26(1), pp. 3-13. doi:10.1038/jhh.2011.3 Retrieved from 10.1038/jhh.2011.3https://www.ncbi.nlm.nih.gov/ pubmed/21307883 Retrieved from https://www.ncbi.nlm.nih.gov/pubmed/21307883 [PubMed: 21307883]

Raziani F, Tholstrup T, Kristensen MD, Svanegaard ML, Ritz C, Astrup A, \& Raben A (2016). High intake of regular-fat cheese compared with reduced-fat cheese does not affect LDL cholesterol or risk markers of the metabolic syndrome: a randomized controlled trial. Am J Clin Nutr, 104(4), pp. 973-981. doi:10.3945/ajcn.116.134932 [PubMed: 27557654]

Sacks FM, Lichtenstein AH, Wu JHY, Appel LJ, Creager MA, Kris-Etherton PM, Van Horn LV (2017). Dietary Fats and Cardiovascular Disease: A Presidential Advisory From the American Heart Association. Circulation, 136(3), pp. e1-e23. doi:10.1161/cir.0000000000000510 [PubMed: 28620111]

Schwab U, Lauritzen L, Tholstrup T, Haldorssoni T, Riserus U, Uusitupa M, \& Becker W (2014). Effect of the amount and type of dietary fat on cardiometabolic risk factors and risk of developing type 2 diabetes, cardiovascular diseases, and cancer: a systematic review. Food Nutr Res, 58doi:10.3402/fnr.v58.25145 Retrieved from 10.3402/fnr.v58.25145https://www.ncbi.nlm.nih.gov/ pubmed/25045347 Retrieved from https://www.ncbi.nlm.nih.gov/pubmed/25045347

Soedamah-Muthu SS, Verberne LD, Ding EL, Engberink MF, \& Geleijnse JM (2012). Dairy consumption and incidence of hypertension: a dose-response meta-analysis of prospective cohort studies. Hypertension, 60(5), pp. 1131-1137. doi:10.1161/HYPERTENSIONAHA.112.195206 Retrieved from 10.1161/HYPERTENSIONAHA.112.195206https://www.ncbi.nlm.nih.gov/ pubmed/22987924 Retrieved from https://www.ncbi.nlm.nih.gov/pubmed/22987924 [PubMed: 22987924]

Soerensen KV, Thorning TK, Astrup A, Kristensen M, \& Lorenzen JK (2014). Effect of dairy calcium from cheese and milk on fecal fat excretion, blood lipids, and appetite in young men. Am J Clin Nutr, 99(5), pp. 984-991. doi:10.3945/ajcn.113.077735 [PubMed: 24622806]

Stonehouse W, Wycherley T, Luscombe-Marsh N, Taylor P, Brinkworth G, \& Riley M (2016). Dairy Intake Enhances Body Weight and Composition Changes during Energy Restriction in 18-50- 
Year-Old Adults-A Meta-Analysis of Randomized Controlled Trials. Nutrients, 8(7), p 394 Retrieved from https://www.mdpi.com/2072-6643/8/7/394

Subar AF, Freedman LS, Tooze JA, Kirkpatrick SI, Boushey C, Neuhouser ML, Krebs-Smith SM (2015). Addressing Current Criticism Regarding the Value of Self-Report Dietary Data. J Nutr, 145(12), pp. 2639-2645. doi:10.3945/jn.115.219634 [PubMed: 26468491]

Sun J, \& Buys N (2015). Effects of probiotics consumption on lowering lipids and CVD risk factors: a systematic review and meta-analysis of randomized controlled trials. Ann Med, 47(6), pp. 430440. doi:10.3109/07853890.2015.1071872 Retrieved from 10.3109/07853890.2015.1071872https://www.ncbi.nlm.nih.gov/pubmed/26340330 Retrieved from https://www.ncbi.nlm.nih.gov/pubmed/26340330 [PubMed: 26340330]

Thorning TK, Bertram HC, Bonjour JP, de Groot L, Dupont D, Feeney E, Givens I (2017). Whole dairy matrix or single nutrients in assessment of health effects: current evidence and knowledge gaps. Am J Clin Nutr, 105(5), pp. 1033-1045. doi:10.3945/ajcn.116.151548 Retrieved from 10.3945/ajcn.116.151548https://www.ncbi.nlm.nih.gov/pubmed/28404576 Retrieved from https:// www.ncbi.nlm.nih.gov/pubmed/28404576 [PubMed: 28404576]

Tian DY, Tian J, Shi CH, Song B, Wu J, Ji Y, Xu YM (2015). Calcium intake and the risk of stroke: an up-dated meta-analysis of prospective studies. Asia Pac J Clin Nutr, 24(2), pp. 245-252. doi:10.6133/apjen.2015.24.2.22 Retrieved from 10.6133/apjen.2015.24.2.22https:// www.ncbi.nlm.nih.gov/pubmed/26078241 Retrieved from https://www.ncbi.nlm.nih.gov/pubmed/ 26078241 [PubMed: 26078241]

U. S. Department of Agriculture. (2018). All About the Dairy Group. Retrieved Date from https:// www.choosemyplate.gov/dairy.

U. S. Department of Health and Human Services, \& U. S. Department of Agriculture. (1980). Nutrition and Your Health. 1980 Dietary Guidelines for AmericansRetrieved from https://health.gov/ dietaryguidelines/1980thin.pdf? _ga=2.262500364.105604531.1561055303-958599651.1561055303

U. S. Department of Health and Human Services, \& U. S. Department of Agriculture. (2005). Chapter 6 Fats. Dietary Guidelines for Americans 2005Retrieved from https://health.gov/dietaryguidelines/ dga2005/document/html/chapter6.htm? _ga $=2.228464541 .105604531 .1561055303-958599651.1561055303$

U. S. Department of Health and Human Services, \& U. S. Department of Agriculture. (2015). 2015 2020 Dietary Guidelines for Americans. 2015-2020 Dietary Guidelines for Americans

Whelton PK, He J, Cutler JA, Brancati FL, Appel LJ, Follmann D, \& Klag MJ (1997). Effects of oral potassium on blood pressure. Meta-analysis of randomized controlled clinical trials. Jama, 277(20), pp. 1624-1632. [PubMed: 9168293]

Wu L, \& Sun D (2017). Consumption of Yogurt and the Incident Risk of Cardiovascular Disease: A Meta-Analysis of Nine Cohort Studies. Nutrients, 9(3)doi:10.3390/nu9030315 Retrieved from 10.3390/nu9030315https://www.ncbi.nlm.nih.gov/pubmed/28327514 Retrieved from https:// www.ncbi.nlm.nih.gov/pubmed/28327514 


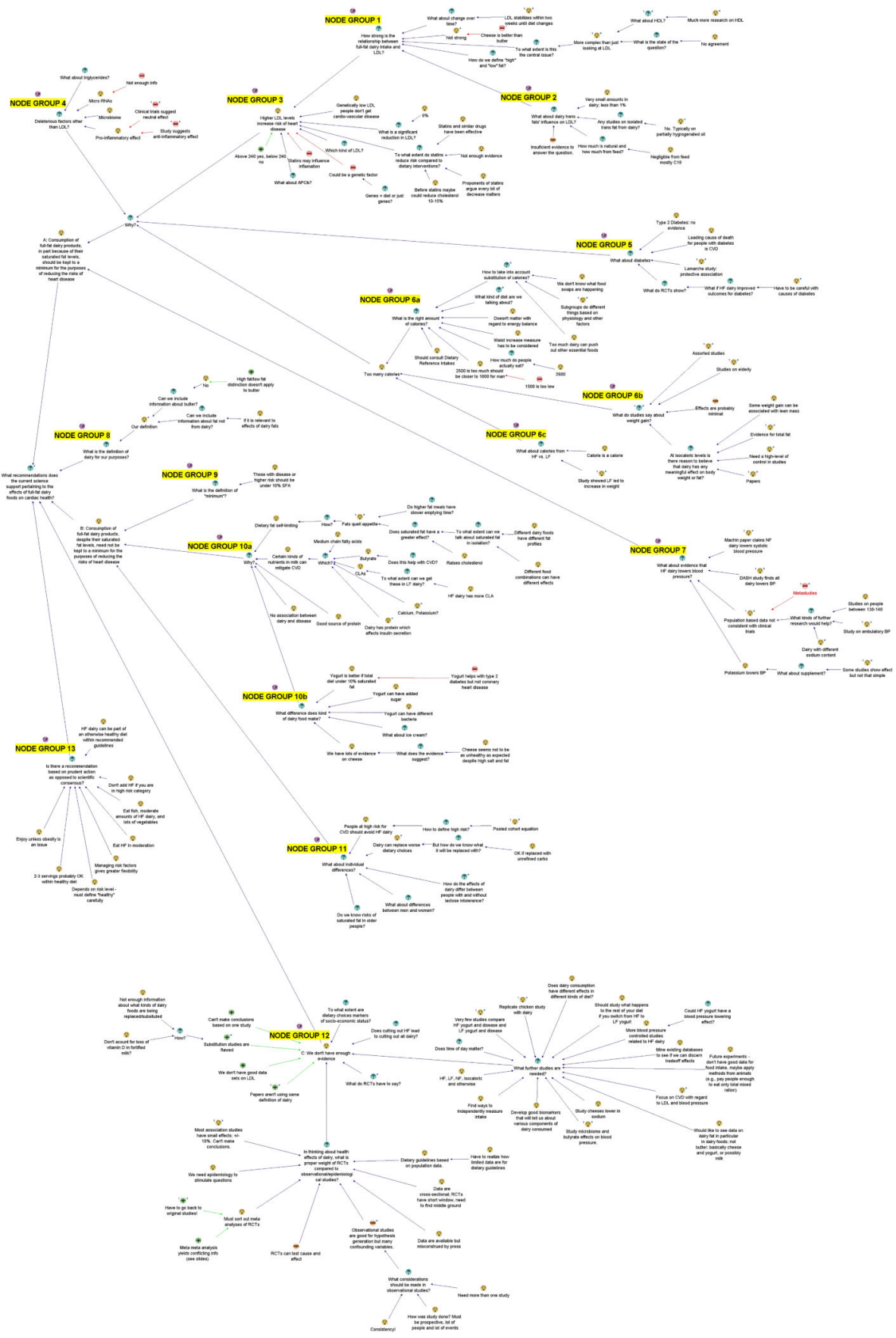

Figure 1. Refined dialogue map.

The dialogue map is composed of connections between nodes, with each node representing an issue/question (question mark icon), idea (light bulb icon), con argument (minus sign), pro argument (plus sign), or agreement (hands shaking icon). Arrows connect related thoughts; an arrow from a new node points to an existing node that the new node builds on. Node groups are marked to highlight branches of the map related to more focused topical discussion, which is schematically summarized in Figure 2. Note that the map is designed to 
be viewed online interactively to see additional details $\left({ }^{*}\right)$ or tagged publications $\left({ }^{\mathrm{T}}\right)$ : https:// dx.doi.org/10.5967/2nxz-f171. 


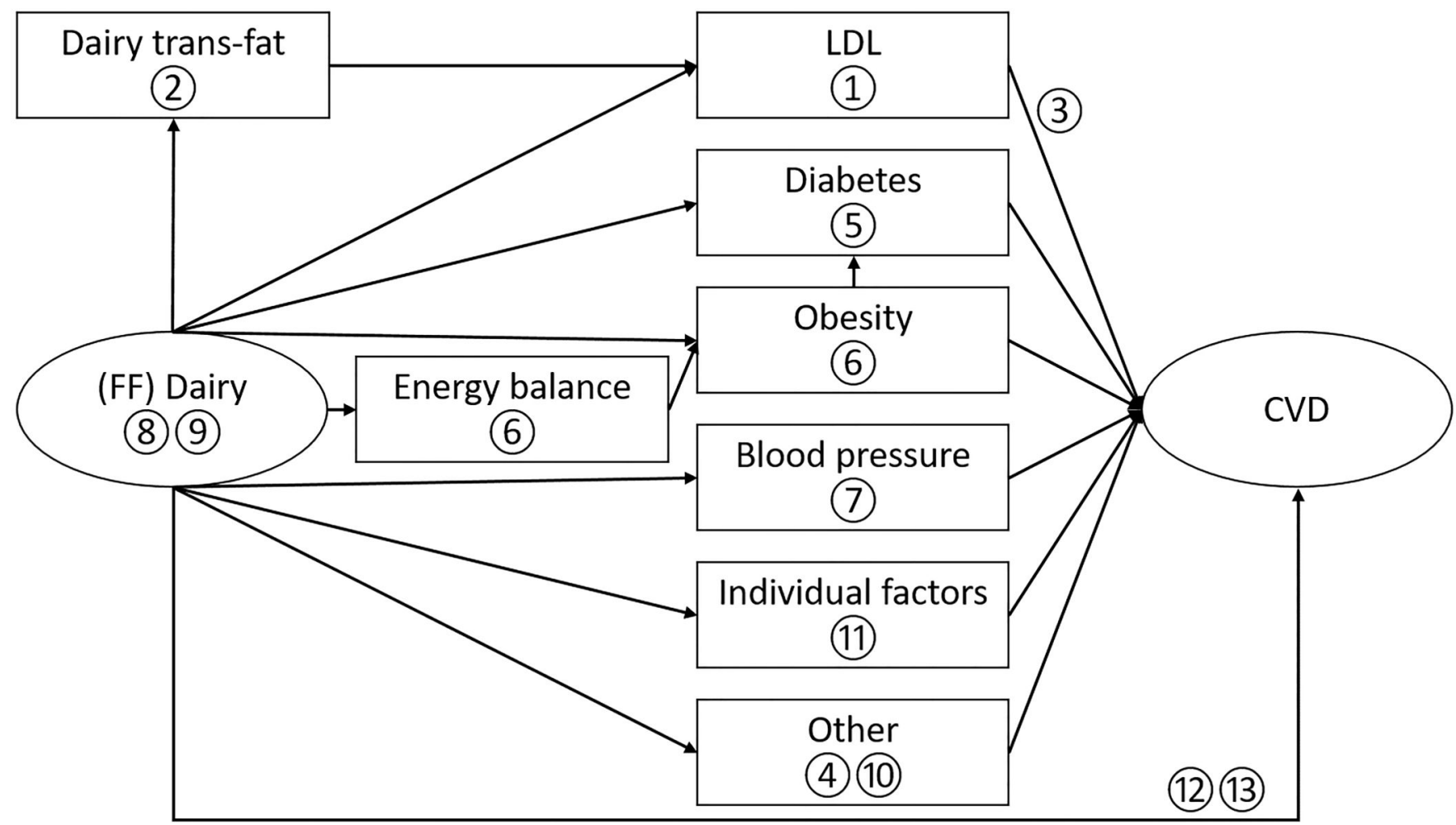

Figure 2. Summary schematic of discussed putative relations between dairy and CVD.

Each arrow is a proposed causal relation, without implying agreement from the panelists on the positive, negative, or null nature of the relation. Circled numbers relate to the numbered node groups from the dialogue map. FF - full-fat; it is noted parenthetically because much discussion revolved around dairy generally. 


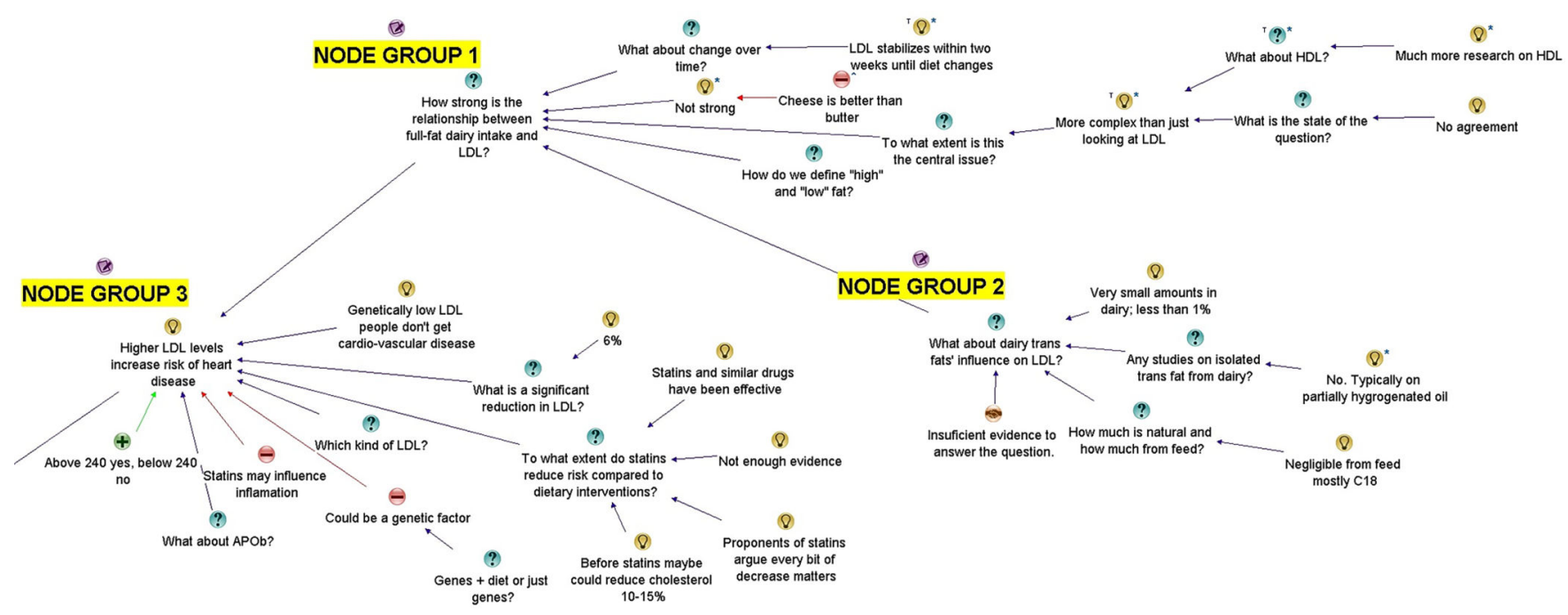

Figure 3. Enlarged portion of map with node groups related to LDL.

The dialogue map (Figure 1) is composed of connections between nodes, with each node representing an issue/question (question mark icon), idea (light bulb icon), con argument (minus sign), pro argument (plus sign), or agreement (hands shaking icon). Arrows connect related thoughts; an arrow from a new node points to an existing node that the new node builds on. Note that the map is designed to be viewed online interactively to see additional details $\left({ }^{*}\right)$ or tagged publications $\left({ }^{\mathrm{T}}\right)$ : https://dx.doi.org/10.5967/2nxz-f171. 


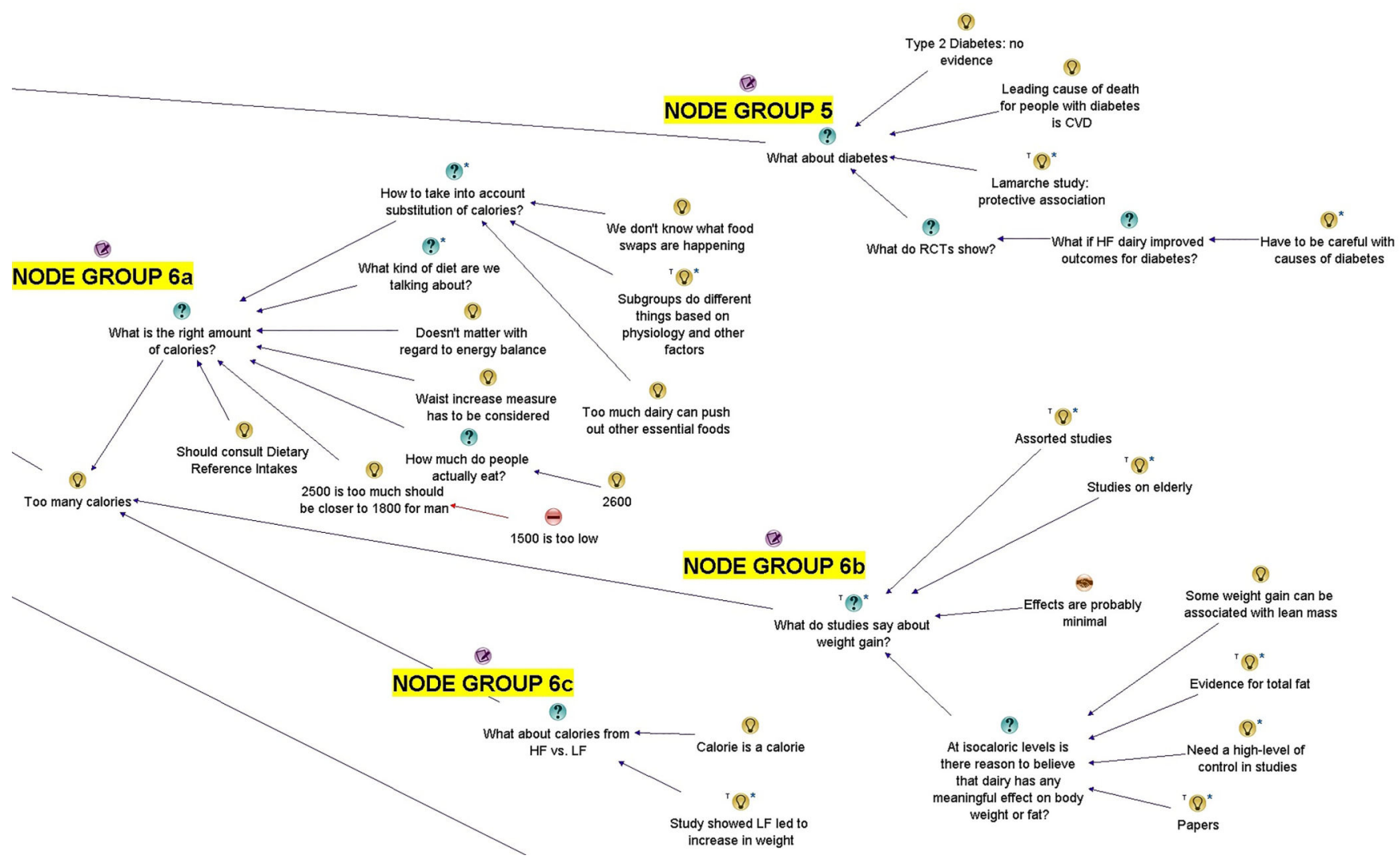

Figure 4. Enlarged portion of map with node groups related to diabetes, obesity, and energy balance.

The dialogue map (Figure 1) is composed of connections between nodes, with each node representing an issue/question (question mark icon), idea (light bulb icon), con argument (minus sign), pro argument (plus sign), or agreement (hands shaking icon). Arrows connect related thoughts; an arrow from a new node points to an existing node that the new node builds on. Note that the map is designed to be viewed online interactively to see additional details (*) or tagged publications $\left({ }^{\mathrm{T}}\right.$ ): https://dx.doi.org/10.5967/2nxz-f171.

Crit Rev Food Sci Nutr. Author manuscript; available in PMC 2022 January 01. 


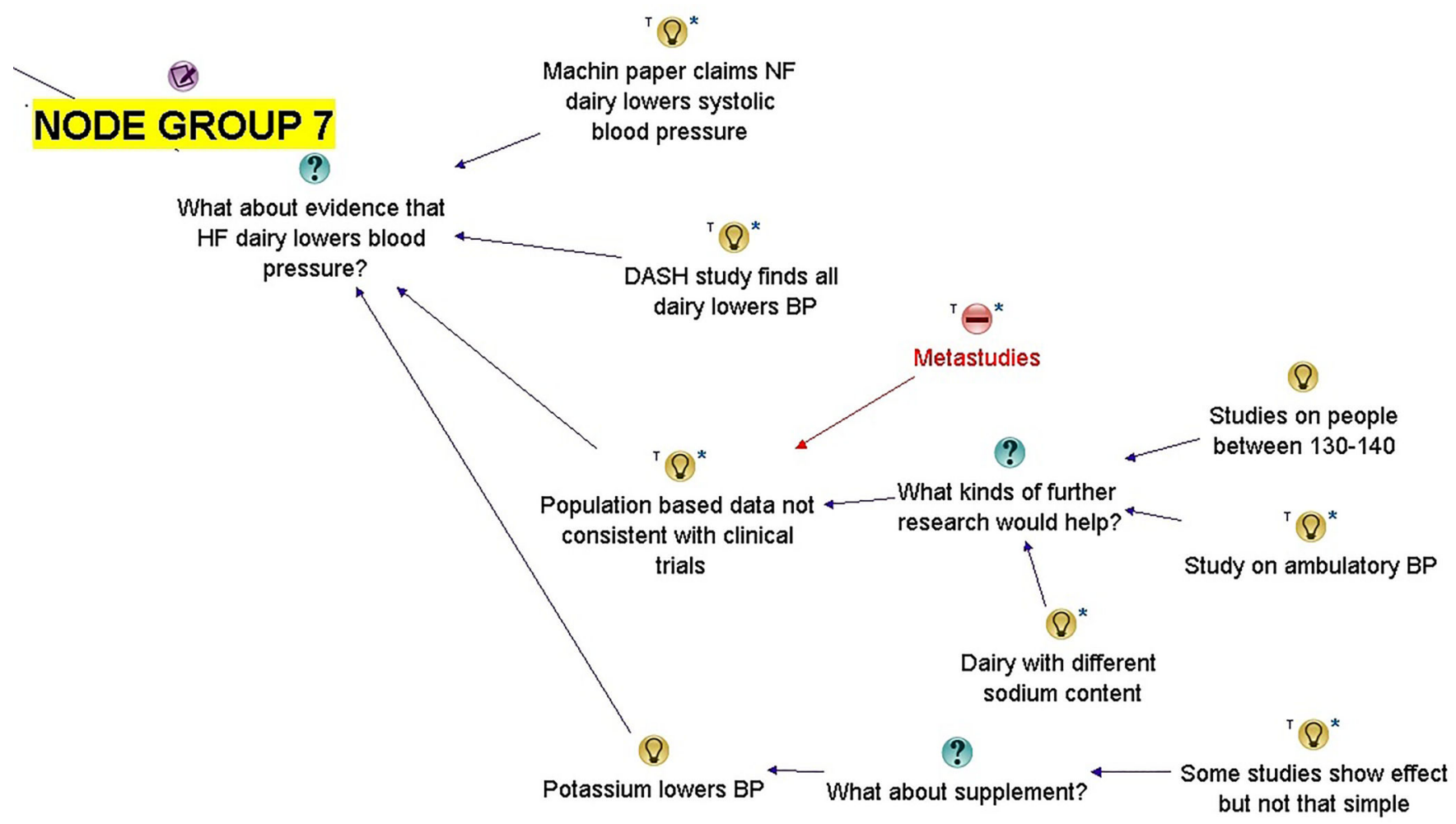

Figure 5. Enlarged portion of map with node groups related to blood pressure.

The dialogue map (Figure 1) is composed of connections between nodes, with each node representing an issue/question (question mark icon), idea (light bulb icon), con argument (minus sign), pro argument (plus sign), or agreement (hands shaking icon). Arrows connect related thoughts; an arrow from a new node points to an existing node that the new node builds on. Note that the map is designed to be viewed online interactively to see additional details $(*)$ or tagged publications $\left({ }^{\mathrm{T}}\right)$ : https://dx.doi.org/10.5967/2nxz-f171. 


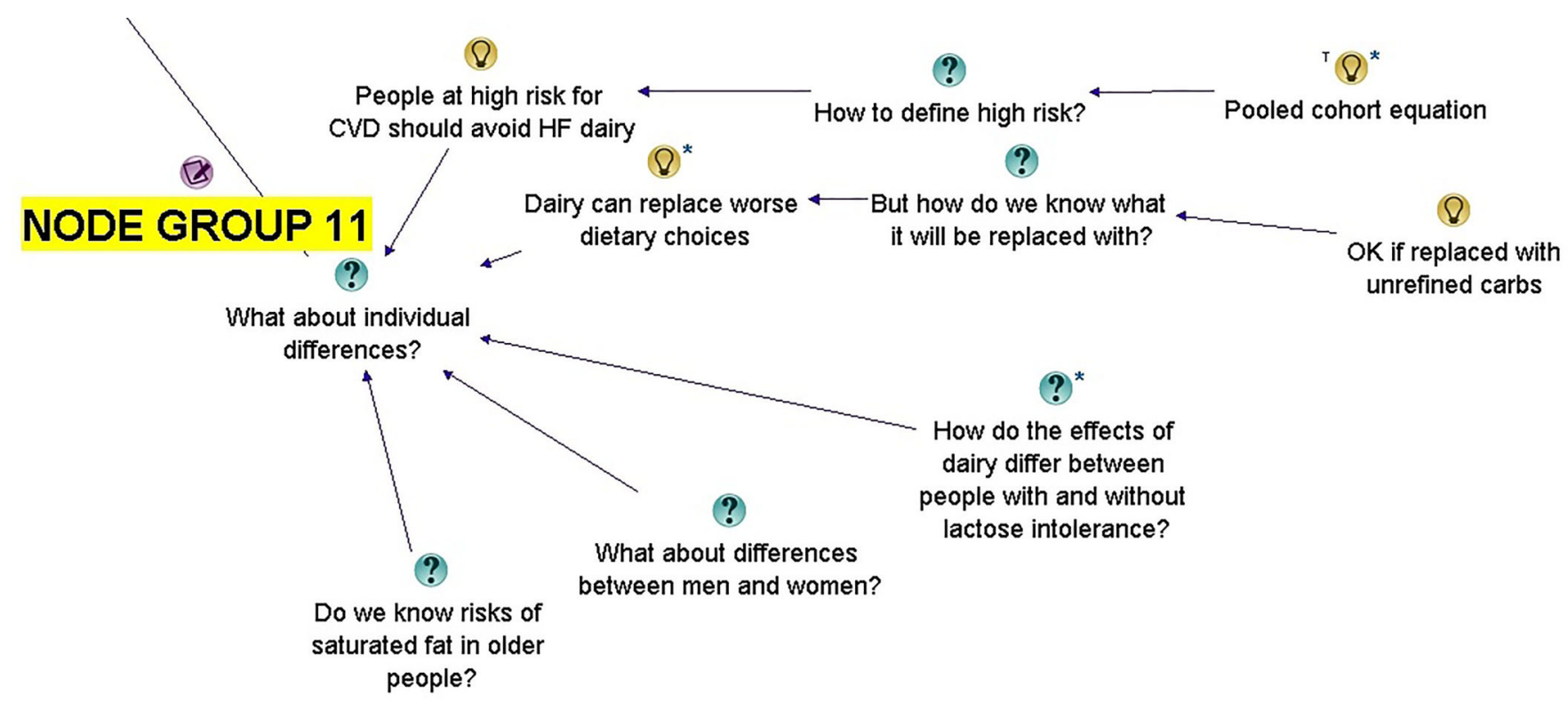

Figure 6. Enlarged portion of map with node groups related to individual factors.

The dialogue map (Figure 1) is composed of connections between nodes, with each node representing an issue/question (question mark icon), idea (light bulb icon), con argument (minus sign), pro argument (plus sign), or agreement (hands shaking icon). Arrows connect related thoughts; an arrow from a new node points to an existing node that the new node builds on. Note that the map is designed to be viewed online interactively to see additional details (*) or tagged publications $\left({ }^{\mathrm{T}}\right)$ : https://dx.doi.org/10.5967/2nxz-f171.

Crit Rev Food Sci Nutr. Author manuscript; available in PMC 2022 January 01. 


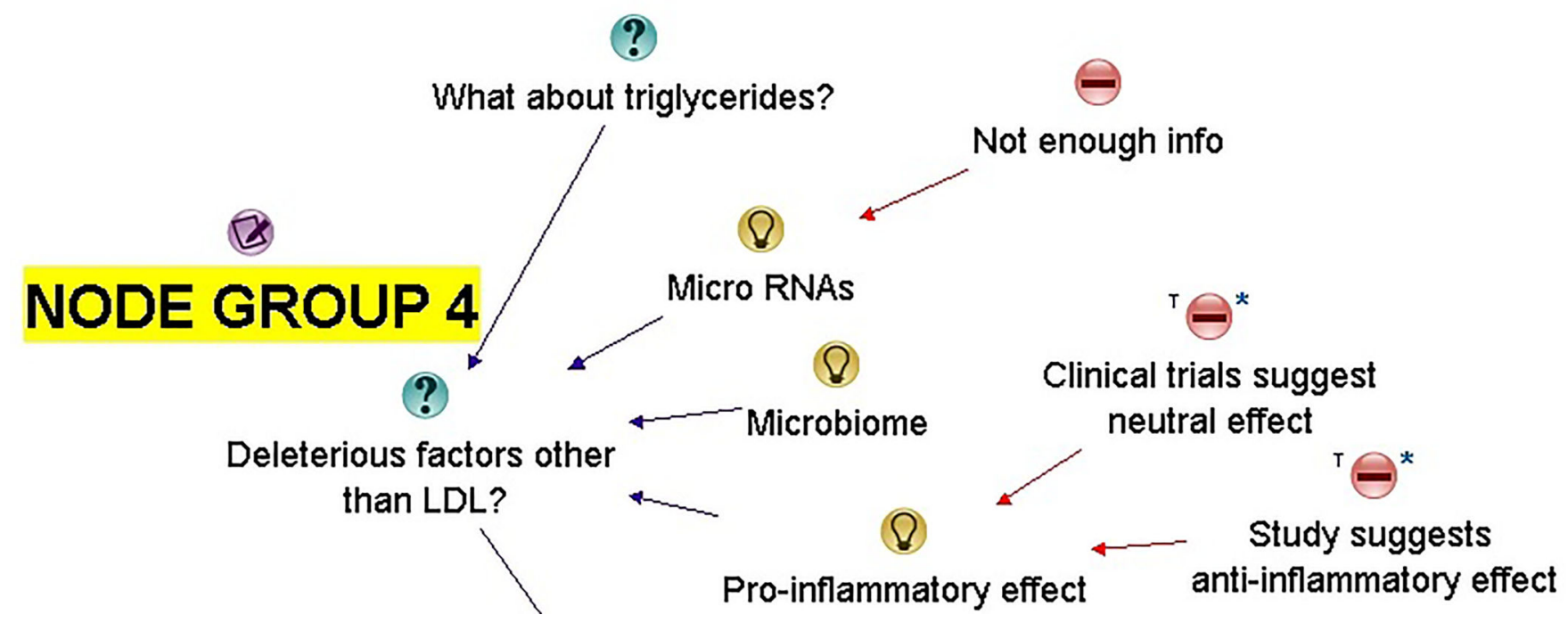

Figure 7. Enlarged portion of map with node groups related to other putative causal pathways. The dialogue map (Figure 1) is composed of connections between nodes, with each node representing an issue/question (question mark icon), idea (light bulb icon), con argument (minus sign), pro argument (plus sign), or agreement (hands shaking icon). Arrows connect related thoughts; an arrow from a new node points to an existing node that the new node builds on. Note that the map is designed to be viewed online interactively to see additional details (*) or tagged publications $\left({ }^{\mathrm{T}}\right)$ : https://dx.doi.org/10.5967/2nxz-f171. 


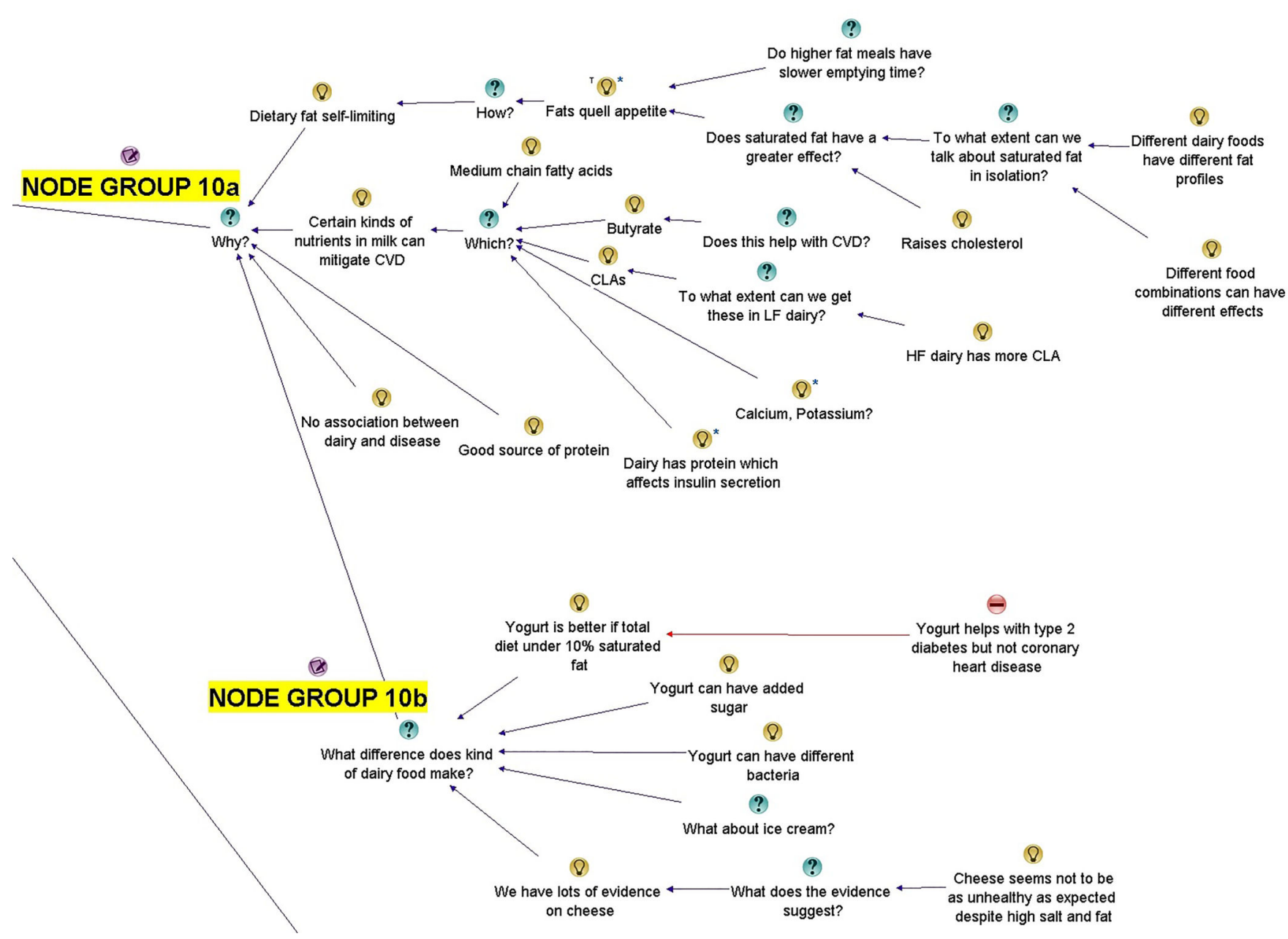

Figure 8. Enlarged portion of map with node groups related to other effects of specific nutrients or dairy foods.

The dialogue map (Figure 1) is composed of connections between nodes, with each node representing an issue/question (question mark icon), idea (light bulb icon), con argument (minus sign), pro argument (plus sign), or agreement (hands shaking icon). Arrows connect related thoughts; an arrow from a new node points to an existing node that the new node builds on. Note that the map is designed to be viewed online interactively to see additional details $(*)$ or tagged publications $\left({ }^{\mathrm{T}}\right)$ : https://dx.doi.org/10.5967/2nxz-f171. 


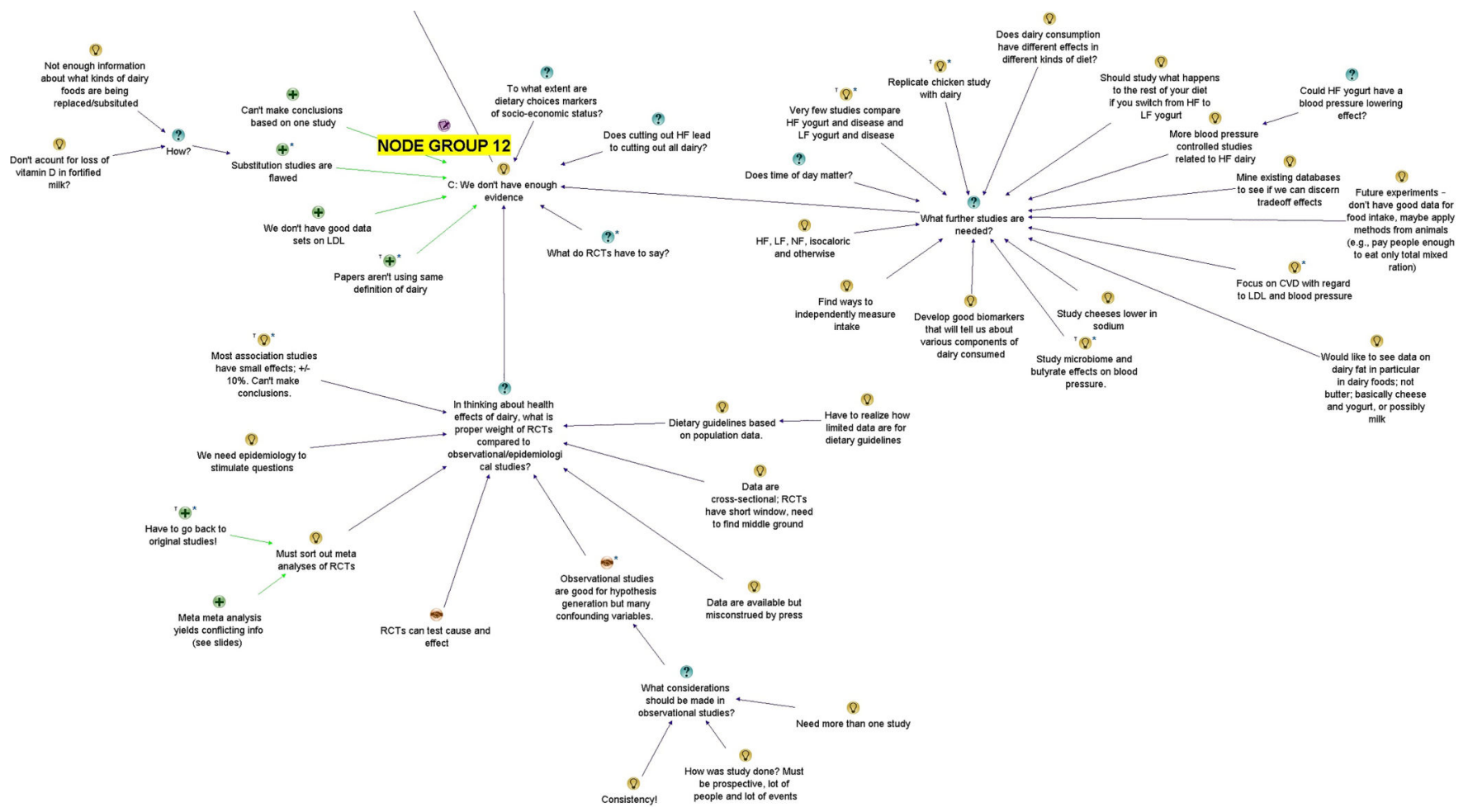

Figure 9. Enlarged portion of map with node groups related to the spontaneous Proposition 2C: "We don't have enough evidence."

The dialogue map (Figure 1) is composed of connections between nodes, with each node representing an issue/question (question mark icon), idea (light bulb icon), con argument (minus sign), pro argument (plus sign), or agreement (hands shaking icon). Arrows connect related thoughts; an arrow from a new node points to an existing node that the new node builds on. Note that the map is designed to be viewed online interactively to see additional details $(*)$ or tagged publications $\left({ }^{\mathrm{T}}\right)$ : https://dx.doi.org/10.5967/2nxz-f171. 

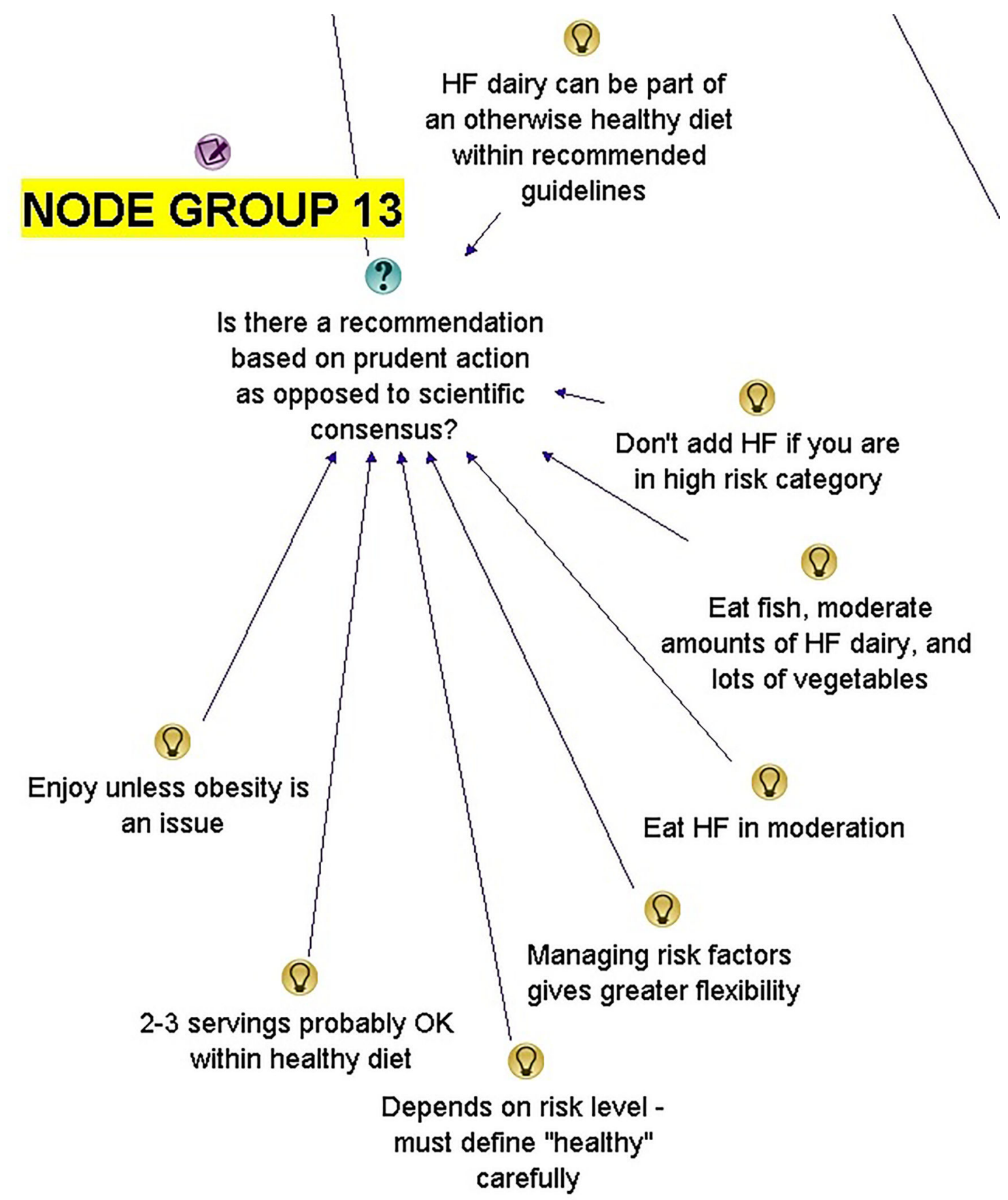

Figure 10. Enlarged portion of map with node groups related to prudent recommendations. The dialogue map (Figure 1) is composed of connections between nodes, with each node representing an issue/question (question mark icon), idea (light bulb icon), con argument (minus sign), pro argument (plus sign), or agreement (hands shaking icon). Arrows connect related thoughts; an arrow from a new node points to an existing node that the new node builds on. Note that the map is designed to be viewed online interactively to see additional details $(*)$ or tagged publications $\left({ }^{\mathrm{T}}\right)$ : https://dx.doi.org/10.5967/2nxz-f171. 